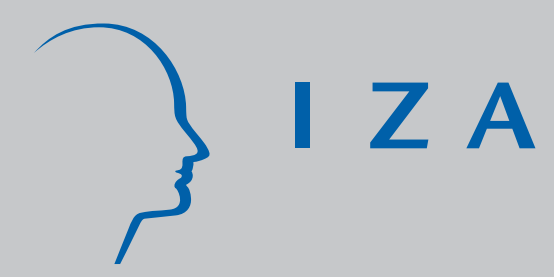

IZA DP No. 2485

How General Is Specific Human Capital?

Christina Gathmann

Uta Schönberg

December 2006 


\title{
How General Is Specific Human Capital?
}

\author{
Christina Gathmann \\ Stanford University \\ and IZA Bonn
}

\author{
Uta Schönberg \\ University of Rochester \\ and IZA Bonn
}

\section{Discussion Paper No. 2485 \\ December 2006}

\author{
IZA \\ P.O. Box 7240 \\ 53072 Bonn \\ Germany \\ Phone: +49-228-3894-0 \\ Fax: +49-228-3894-180 \\ E-mail: iza@iza.org
}

\begin{abstract}
Any opinions expressed here are those of the author(s) and not those of the institute. Research disseminated by IZA may include views on policy, but the institute itself takes no institutional policy positions.
\end{abstract}

The Institute for the Study of Labor (IZA) in Bonn is a local and virtual international research center and a place of communication between science, politics and business. IZA is an independent nonprofit company supported by Deutsche Post World Net. The center is associated with the University of Bonn and offers a stimulating research environment through its research networks, research support, and visitors and doctoral programs. IZA engages in (i) original and internationally competitive research in all fields of labor economics, (ii) development of policy concepts, and (iii) dissemination of research results and concepts to the interested public.

IZA Discussion Papers often represent preliminary work and are circulated to encourage discussion. Citation of such a paper should account for its provisional character. A revised version may be available directly from the author. 


\section{ABSTRACT}

\section{How General Is Specific Human Capital?*}

Previous studies assume that labor market skills are either fully general or specific to the firm. This paper uses patterns in mobility and wages to analyze how portable specific skills are in the labor market. The empirical analysis combines data on tasks performed in different jobs with a large panel on complete working histories and wages. Our results demonstrate that labor market skills are partially transferable across occupations. We find that individuals move to occupations with similar task requirements and that the distance of moves declines with time in the labor market. Further, tenure in the last occupation affects current wages, and the effect is stronger if the two occupations are similar. Our estimates suggest that taskspecific human capital is the most important source of wage growth for university graduates. For the low- and medium-skilled, returns to task human capital are also sizeable, though smaller than for labor market experience.

JEL Classification: J24, J41, J62

Keywords: $\quad$ specific skills, occupations, wage growth, mobility

Corresponding author:

Christina Gathmann

Hoover Institution

Stanford University

Stanford, CA 94305-6010

USA

E-mail: cgathman@stanford.edu

\footnotetext{
* We thank Katherine Abraham, Mark Bils, Nick Bloom, Susan Dynarski, Bernd Fitzenberger, Anders Frederiksen, Donna Ginther, Galina Hale, Bob Hall, Dan Kessler, Pete Klenow, Ed Lazear, Rasmus Lentz, Petra Moser, John Pencavel, Luigi Pistaferri, Michele Tertilt, participants at SOLE, the SED, the World Congress of the Econometric Society in London and numerous institutions for helpful comments and suggestions. All remaining errors are our own.
} 


\section{Introduction}

The distinction between general and specific human capital is a central concept in labor economics. Specific human capital plays an important role for questions like: Does job displacement lead to substantial losses of human capital? Are skills specific to a technology and depreciate in periods of rapid technological change? Do specific skills slow down the adjustment to new technologies? ${ }^{1}$ To answer these and similar questions, we need to understand how portable specific skills are in the labor market.

Human capital and job search models are built on the assumption that specific skills are tied to a firm or an occupation. This assumption implies that specific skills are fully lost when an individual leaves that particular firm or occupation. In this paper, we analyze whether specific skills are more generally transferable across firms and occupations. ${ }^{2}$ Compare for instance a carpenter who decides to become a cabinet maker with a carpenter who decides to become a baker. In our approach, the former can transfer more skills to his new occupation than the latter.

The economic idea behind our approach is as follows. Suppose there are two types of skills in the labor market, for example analytical and manual skills. Both skills are general in the sense that they are productive in many occupations. Occupations combine these two skills in different ways. For example, one occupation might rely heavily on analytical skills, a second more on manual skills, and a third combines the two in equal proportion. Human capital accumulated while working in an occupation is then 'specific' to that occupation to the extent that occupations place different values on combinations of skills (see also Lazear, 2004). We refer to this type of human capital as skill- or task- specific. ${ }^{3}$

To analyze the transferability of human capital empirically, we require high-quality data on both worker mobility and the skill requirements in different occupations. We construct such a data set by

\footnotetext{
${ }^{1}$ Recent macroeconomic models have argued that the specificity of skills with respect to the current technology plays a crucial role in explaining the divergent growth experience of the United States and Europe (Krueger and Kumar, 2004; Wasmer, 2005) and the rise in wage inequality over the past two decades (Violante, 2002; Kambourov and Manovskii, 2004).

${ }^{2}$ Human capital theory focuses on the contributions of general skills like experience and skills specific to a firm or occupation for indvidual wage growth (Becker, 1964; Mincer, 1974). Job search models focus on firm-specific skills as determinants of job mobility behavior (Jovanovic, 1979a; 1979b; Flinn, 1986; Topel and Ward, 1992). Some models consider both occupational and firm mobility (McCall, 1990; Miller, 1984; Neal, 1998; Pavan, 2005). Like models on firm mobility, these models assume that the worker's current occupation does not affect the direction of occupational mobility.

${ }^{3}$ Throughout the paper, we use these two terms interchangeably.
} 
matching information from two different data sources in Germany. The first data set is a large survey that provides detailed information on 19 different tasks performed in occupations at four separate points in time. Using this variation in task usage across occupations, we construct measures of 'distance' between occupations. Based on the task data, the skill requirements of a baker and a cook are very similar. In contrast, switching from a banker to an unskilled construction worker would be the most distant move observable in our data.

The second data source is a large panel that follows individual labor market careers from 1975 to 2001. The data, derived from a two percent sample of all social security records in Germany, provides a complete picture of job mobility and wages with more than one million observations. Its administrative nature ensures that there is little measurement error in wages and occupational coding. Both are serious problems in data sets like the PSID or NLSY used in the previous literature on occupational mobility. In addition, we have much larger samples available than in typical household surveys. Matching the information on tasks and distance between occupations to the individual panel data on mobility and wages, we can link observable patterns in mobility and wages to the transferability of skills in an innovative way.

Our results suggest that task-specific human capital is important to understand both job mobility behavior and individual wage growth. We find that individuals are much more likely to move to similar occupations than suggested by standard turnover models. Both the distance of actual moves and the propensity to switch occupations declines sharply with labor market experience. This is consistent with the idea that the accumulation of task-specific human capital makes mobility to distant occupations increasingly costly.

If human capital is task specific and therefore in part transferable across occupations, this should also be reflected in individuals' wages. Our framework can explain why tenure in the pre-displacement job has been found to have a positive effect on the post-displacement wage (Kletzer, 1989). We also show that wages and tenure in the last occupation have a stronger effect on wages in the new occupation if the two occupations require similar skills. 
We then quantify the contribution of task-specific human capital to individual wage growth relative to other general and specific skills. Our estimates show that task-specific human capital is an important determinant of individual wage growth, in particular for university graduates. Based on our estimates, we calculate the costs of job displacement under alternative assumptions on skill transferability. Wage losses of displacement are similar across education groups, and vary substantially with the type of the occupational move after displacement.

Our paper is related to several strands in the literature on labor market skills. A large number of studies have estimated the contribution of firm-specific human capital to individual wage growth. While estimates of the returns to firm tenure find conflicting estimates (Abraham and Farber, 1987; Altonji and Shakotko, 1987; Altonji and Williams, 2005; Topel, 1991), studies of wage losses after job displacement suggest that specific skills are important (Jacobson et al., 1993; Kletzer, 1989).

Recent evidence suggests that specific skills might be more tied more to an occupation than to a particular firm. Several studies have shown that the coefficient on firm tenure in a wage regression declines if one controls for occupational or industry tenure (Gibbons et al., 2006; Kambourov and Manovskii, 2002; Parent, 2000). Similarly, evidence from displaced workers demonstrates that wage losses are much lower if workers return to the sector of their pre-displacement job (Neal, 1999).

The approach and evidence presented in this paper suggest that specific skills are more portable than previously thought. Human capital accumulated in the labor market is not fully lost if an individual leaves a firm or occupation. On the contrary, task-specific skills are an important source of wage growth over the life-cycle, in particular for university graduates.

Only few studies adopt an approach similar to ours, and analyze whether specific skills are valuable in other occupations or industries ${ }^{5}$. Shaw (1987) finds that skills accumulated in one occupation are valued in related occupations. Poletaev and Robinson (2004) provide evidence that wage losses after job displacement are lower if the main task on the job remains the same as prior to displacement. This

\footnotetext{
${ }^{4}$ See Farber (1999) for a comprehensive survey of this literature.

${ }^{5}$ In a related approach, Malamud (2005) analyzes the relatedness between university education and occupations.
} 
paper deviates from this literature in at least three ways: first, we analyze how task-specific human capital affects job mobility behavior. Second, we construct a continuous measure of distance between occupations based on information about tasks performed in occupations. Finally, we are able to quantify the contribution of task human capital to wage growth over the life cycle and compare that to the returns of alternative measures of specific skills.

Other work has studied the importance of different types of skills for labor market outcomes. For example, Borghans et al.(2006) provide evidence that workers sort into occupations based on their interpersonal skills. Autor et al. (2003) and Spitz-Oener (2006) find that technological change has shifted skill requirements away from routine work to non-routine analytical tasks. Ingram and Neumann (2004) argue that changes in the returns to tasks performed on the job are an important determinant of wage differentials across education groups.

In contrast, the goal of this paper is to understand how portable specific skills are on average. We therefore abstract from which types of tasks matter for wages or how individuals with different endowments sort into occupations. Instead, we focus on how important task-specific human capital is for labor market outcomes relative to general human capital or skills tied to a firm or occupation.

The paper proceeds as follows. The next section outlines our concept of task human capital and its consequences for occupational mobility and individual wage growth. Section 3 introduces the two data sources and how we relate occupations to each other in terms of their task usage. The empirical results on the similarity of occupational moves and its implications for wages across occupations are presented in Section 4. Section 5 estimates the importance of task-specific human capital for wage growth. Section 6 discusses future extensions and concludes.

\section{Economic Mechanism}

This section introduces our concept of task-specific human capital and defines how occupations are related to each other. We then extend the existing framework on specific skills to account for the contribution 
of task-specific human capital to individual wage growth.

\subsection{Task-Specific Human Capital}

Theories on human capital or job search distinguish between general skills (like education and labor market experience), and skills more specific to the firm or occupation. Both traditions share the assumption that an individual's current occupation does not affect the direction of occupational mobility. This assumption implies that a carpenter who becomes a banker is able to transfer as many skills as a carpenter who becomes a cabinet maker. As we show in Section 4, this assumption is not supported by the data. Our approach relaxes this assumption.

We assume that output in an occupation is produced by combining different tasks, for example negotiating, teaching or managing personnel. These tasks are general in the sense that they are productive in different jobs (e.g. Heckman and Sedlacek, 1986). Occupations differ in which tasks they require and in the relative importance of each task for production. Human capital accumulated while working in an occupation is then 'specific' to that occupation to the extent that occupations place different values on combinations of skills. We refer to this type of human capital as skill- or task-specific. ${ }^{6}$

More specifically, consider the case of two tasks, denoted by $j=A, M$. We think of them as manual and analytical tasks. Occupations combine the two skills in different ways. For example, one occupation might rely heavily on analytical skills, a second more on manual skills, and a third combines the two in equal proportion. Let $\beta_{o}\left(0 \leq \beta_{o} \leq 1\right)$ be the relative weight on the analytical task, and $\left(1-\beta_{o}\right)$ be the relative weight on the manual task. For example, if in an occupation analytical tasks are more important than manual tasks, $\beta_{o}>0.5$. In another occupation, only the manual task might be performed, so $\beta_{o}=0$. By restricting the weights on the tasks to sum to one, we focus on the relative importance of each task, not on the task intensity in an occupation.

In this framework, we can define the relation between occupations in a straightforward way. Two

\footnotetext{
${ }^{6}$ Our definition of task-specific human capital differs from that by Gibbons and Waldman (2006). In their setup, task human capital is specific to the job within a firm and might therefore not be transferable across jobs within the same firm.
} 
occupations $o$ and $o^{\prime}$ are similar if they employ analytical and manual tasks in similar proportions, i.e. $\beta_{o}$ is close to $\beta_{o^{\prime}}$. We can then measure the distance between the two occupations as the absolute difference between the weight given to the analytic task in each occupation, i.e. $\left|\beta_{o}-\beta_{o^{\prime}}\right|$. In this setup, the occupation that fully specializes in the analytical task $\left(\beta_{o}=1\right)$ and the one that fully specializes in the manual task $\left(\beta_{o}=0\right)$ are the two most distant occupations; the distance between these two occupations is equal to one.

Suppose further that at labor market entry, individuals are endowed with a productivity in each task. It may vary over the life-cycle for instance because workers receive new information about their talent in each task. With time in the labor market workers become more productive in each task through learning-by-doing. We assume that if a person switches occupations, the distance between the source and target occupation determines how much skills are transferable to the new occupation. Individuals who move to an occupation with similar skill requirements are able to transfer more skills than workers who move to a very different occupation. More specifically, we assume that workers can transfer a fraction $1-\left|\beta_{o}-\beta_{o^{\prime}}\right|$ of their human capital if they switch from occupation $o$ to $o^{\prime}$. For example, if workers move from an occupation that fully specializes in the analytical task $\left(\beta_{o}=1\right)$ to an occupation that fully specializes in the manual task $\left(\beta_{o^{\prime}}=0\right)$, none of the acquired skills can be transferred. If, in contrast, workers move from an occupation that mostly uses the analytical task (e.g. $\left.\beta_{o}=0.75\right)$ to an occupation that employs both tasks in equal proportions (e.g. $\beta_{o^{\prime}}=0.5$ ), they are able to transfer 75 percent of their acquired skills. Consequently, task-specific human capital is neither purely general, nor purely specific, but partially transferable across occupations.

\subsection{Wages and the Returns to General and Specific Skills}

This section discusses how we can include task-specific human capital into the existing framework on the returns to general and specific skills. Previous studies on specific human capital (e.g. Kambourov and Manovskii, 2002; Parent, 2000; Neal, 1999) typically specify (log-) wages of worker $i$ in firm $j$ and 
occupation $o$ and time $t$ as follows:

$$
\begin{aligned}
\ln w_{i j o t} & =P_{o}+\gamma_{1} E_{i t}+\gamma_{2} O T_{i o t}+\gamma_{3} F T_{i j t}+u_{i j o t} \\
u_{i j o t} & =a_{i}+o_{i o t}+f_{i j t}+\varepsilon_{i j o t} .
\end{aligned}
$$

This specification emphasizes that workers become more productive with time in the labor market through human capital accumulation. The specification allows for three types of human capital. $E_{i t}$ (actual experience) measures general human capital that is equally valued across all firms and occupations in the economy. $O T_{i o t}$ (occupational tenure) and $F T_{i j t}$ (firm tenure) reflect occupation- and firm-specific human capital that is fully lost once a worker leaves the occupation or firm. $\gamma_{1}, \gamma_{2}$ and $\gamma_{3}$ denote the return to general, occupation- and firm-specific human capital respectively. $P_{o}$ is an occupation fixed effect, and may be viewed as the price of occupation-specific skills in occupation $o$.

The unobserved (for the econometrician) error term $u_{i j o t}$ is decomposed into a fixed worker effect $\left(a_{i}\right)$, a possibly time-varying occupation-specific $\left(o_{i o t}\right)$ and firm-specific $\left(f_{i j t}\right)$ match effect, and an i.i.d. error term $\left(\epsilon_{i j o t}\right)$. The fixed worker effect captures permanent differences in worker productivity that is equably valuable across all firms and occupations in the economy. The occupation- and firm-specific match quality reflects productivity differences across firms and occupations. In line with the concept of purely firmand occupation-specific human capital, match-specific productivity is assumed to be uncorrelated across firms and occupations. It may vary over time for instance because workers receive new information about their productivity in the occupation or firm. The i.i.d. error term $\varepsilon_{i j o t}$ reflects measurement error or other idiosyncratic differences in wages across workers.

As noted above, the specification in (1) assumes that occupation-specific skills are fully lost if an individual switches occupations. In contrast, we allow for specific skills to be transferable across occupations. To incorporate task-specific human capital into the framework above, we follow the literature in assuming each individual accumulates the same amount of human capital in each occupation and firm. 
This implies that the accumulation of task-specific human capital does neither depend on individuals' initial endowments (as in Ben-Porath , 1967) nor on the occupational choice (as in Rosen, 1983; Murphy, 1986). This restriction keeps the setup empirically tractable and allows us to focus our analysis on the importance of task human capital for occupational mobility and individual wage growth. ${ }^{7}$

In particular, we define task-specific human capital of individual $i$ as:

$$
\text { TaskHC } C_{i t}=T T_{i t}+\left\{\beta_{o} T_{i t}^{A}+\left(1-\beta_{o}\right) T_{i t}^{M}\right\}
$$

where $T T_{i t}$ denotes observable task tenure. This component evolves according to $T T_{i t+1}=1+T T_{i t}$ for occupational stayers and $T T_{i t+1}=1+\sum_{o^{\prime}=1}^{O}\left(1-\left|\beta_{o}-\beta_{o^{\prime}}\right|\right) * O T_{i o^{\prime} t}$ for occupational switchers, where $o$ denotes the workers' current, and $o^{\prime}(1, \ldots, O)$ workers' past occupations (see discussion above $)^{8}$. The second component $\left\{\beta_{o} T_{i t}^{A}+\left(1-\beta_{o}\right) T_{i t}^{M}\right\}$ is unobservable (to the econometrician). It consists of worker's productivity in task $A$ and $M$ at time $t$, denoted by $T_{i t}^{A, M}$, multiplied by the occupationspecific weights on the two tasks. The unobserved component of task human capital evolves according to $T_{i t+1}^{A, M}=T_{i t}^{A, M}+e_{i t+1}^{A, M}$ where the productivity shocks are assumed to be iid.

The definition of task-specific human capital in (2) suggests the following extension of the standard log-wage regression:

$$
\ln w_{i j o t}=P_{o}+\gamma_{1} E_{i t}+\gamma_{2} O T_{i o t}+\gamma_{3} F T_{i j t}+\gamma_{4} T T_{i o t}+u_{i j o t}
$$

where $\gamma_{4}$ denotes the return to task-specific human capital as measured by task tenure $T T_{i t}$. The unob-

\footnotetext{
${ }^{7} \mathrm{~A}$ more general model of occupational choice and human capital accumulation would allow workers to invest separately in task-specific skills $A$ and $M$. For instance, learning a task could depend on the usage of a task in an occupation. If a worker chooses an occupation that mainly specializes in task $A$, he would mainly accumulate skills in task $A$. This ties the skill investment decision to the choice of an occupation. See Murphy (1986) or Rosen (1983) for models along these lines. However, this more general model would not lead to an empirical specification we can estimate with the data available to us.

${ }^{8}$ For example, consider a worker who is currently working in occupation C, and who has worked for one year in occupation A and for another year in occupation B. Suppose that the distance between occupation A and C is 0.2 and between B and $\mathrm{C}$ 0.8. His task tenure in occupation $\mathrm{C}$ is then 1 (occupation $\mathrm{C}$ ) $+(1-0.2)^{*} 1$ (occupation $\left.\mathrm{A}\right)+(1-0.8) * 1$ (occupation B). Hence, occupation tenure in each previous occupation is inversely weighted by the distance between the current and previous occupations.
} 
served error term is now given by

$$
u_{i j o t}=a_{i}+\left\{\beta_{o} T_{i t}^{A}+\left(1-\beta_{o}\right) T_{i t}^{M}\right\}+f_{i j t}+\varepsilon_{i j o t} .
$$

In our setup, the occupation-specific match $\beta_{o} T_{i t}^{A}+\left(1-\beta_{o}\right) T_{i t}^{M}$ consists of an individual's unobserved task productivity weighted by the relative importance of a task in the particular occupation. ${ }^{9}$

In this framework, workers who are particularly productive in analytical or manual tasks choose occupations that specialize in that task. In contrast, workers who are equally talented in both tasks prefer occupations that give a similar weight to each task. We would like to stress that it is predominantly the relative task productivity that determines occupational choice: Doubling productivity in both tasks will have little impact on workers' occupational choice.

When deciding whether to switch occupations, workers trade off the loss in occupation- and task specific human capital $\left(O T_{i o t}, T T_{i o t}\right)$ to the gain in task-specific $\left(\beta_{o} T_{i t}^{A}+\left(1-\beta_{o}\right) T_{i t}^{M}\right)$ and firm-specific $\left(f_{i j t}\right)$ productivity. Our framework implies that, everything else equal, workers are more likely to move to occupations in which they can perform similar tasks as in their previous occupation. One reason is that the probability to receive an occupational or firm match that compensates for the loss in task- and occupation-specific human capital in a distant occupation is low. Furthermore, previously accumulated task-specific human capital is more valuable in a similar than in a distant occupation, which makes similar occupations more attractive relative to distant occupations.

Below, we present several pieces of evidence that task human capital is important for understanding job mobility and wage growth. In Section 4, we document patterns in occupational mobility and wages of occupational movers that are consistent with our definition of task human capital. These patterns are difficult to reconcile with the standard approach that assumes that the direction of occupational mobility is independent of accumulated skills. Based on (3) and (4), we then estimate the return to task-specific

\footnotetext{
${ }^{9}$ One could imagine that there is in addition an occupation-specific component $o_{i o t}$ that is uncorrelated across occupations. Since the two occupation-specific unobservables $o_{i o t}$ and $\beta_{o} T_{i t}^{A}+\left(1-\beta_{o}\right) T_{i t}^{M}$ are econometrically equivalent, we abstract from the first on here.
} 
human capital and compare it to the returns for general and occupation-specific skills (Section 5).

\section{Data Sources and Descriptive Evidence}

To study patterns in mobility and wages across occupations, we combine two different data sources from Germany. We describe each of them in turn. Details on the definition of variables and sample construction can be found in Appendix A.

\subsection{Data on Tasks Performed in Occupations}

Our first data set contains detailed information on tasks performed in different occupations, which we use to construct a measure of how similar or distant occupations are in their skill requirements. The data come from the repeated cross-section German Qualification and Career Survey, which is conducted jointly by the Federal Institute for Vocational Education and Training (BIBB) and the Institute for Employment (IAB) to track skill requirements of occupations. The survey, previously used for example by DiNardo and Pischke (1997) and Borghans et al. (2006), is available for four different years: 1979, 1985, 1991/92 and 1998/99. Each wave contains information from 30,000 employees between the ages of 16 and 65 . In what follows, we restrict our analysis to men since men and women differ significantly in their work attachments and occupational choices.

In the survey, individuals are asked whether they perform any of nineteen different tasks in their job. Tasks vary from repairing and cleaning to buying and selling, teaching, and planning. For each respondent, we know whether he performs a certain task in his job and whether this is his main activity. Table B1 lists the fraction of workers performing each of the nineteen different tasks. ${ }^{10}$ Following Autor et al. (2003) and Spitz-Oener (2006), we combine the 19 tasks into three aggregate groups: analytical tasks, manual tasks and interactive tasks. On average, 55 percent report performing analytic tasks, 72

\footnotetext{
${ }^{10}$ The survey does not report how much time workers spend on each task. Our task data and derived measures thus use variation in task requirements across occupations and over time. The data therefore do not reflect changes in the task over time (for example, computing skills) or individual specialization within tasks (for example, what type of law or medicine is practiced).
} 
percent manual tasks, and 49 percent interactive tasks. The picture for the main task used is similar: 32 percent report analytical tasks, 57 percent manual tasks and 28 percent interactive tasks as their main activity on the job.

The last two columns in Table B1 show the distribution of tasks performed on the job for two popular occupations: teacher and baker. According to our task data, a teacher primarily performs interactive tasks (95.3 percent) with teaching and training others being by far the most important one (91.4 percent). Two other important tasks are correcting texts or data (39.6 percent) and organize, coordinate, manage personnel (39.4 percent). A baker in contrast is a primarily manual occupation (96.4 percent) with manufacturing, producing, installing as the most important task (87.9 percent) followed by teaching and training others (34.3 percent) as well as organizing, coordinating and managing personnel (29.9 percent).

To see how task usage varies across occupations, Table B2 lists the fraction of workers performing manual, analytical, and interactive tasks for all 64 occupations. The table shows that there is a lot of variation in task usage across occupations. For example, while the average use of analytical tasks is 56.3 percent, the mean varies from 16.7 percent as an unskilled construction worker to 92.4 percent for an accountant. The variation is similar if we focus on the main activity performed in occupations instead.

We next explain how we use information on task usage to characterize the distance between occupations in terms of their skill requirements.

\subsection{Measuring the Distance between Occupations}

According to our framework, two occupations have similar skill requirements if they put similar weights on tasks, i.e. individuals perform the same set of tasks. With two tasks, the maximum distance between two occupations occurs if occupation $o$ only uses task $A\left(\beta_{o}=1\right)$, and occupation $o$ only task $M\left(\beta_{o^{\prime}}=0\right)$. The basic idea extends naturally to our case with more than two tasks.

We use the differences in reported usage summed over all the nineteen tasks as our empirical measure 
of distance between occupation $o$ and occupation $o^{\prime}$. More formally, the distance measure is

$$
D i s_{o o^{\prime}}=\frac{1}{J} \sum_{j=1}^{J}\left|\frac{q_{j o}}{q_{o}}-\frac{q_{j o^{\prime}}}{q_{o^{\prime}}}\right|
$$

where $\frac{q_{j o}}{q_{o}}$ denotes the fraction of workers in occupation $o$ who perform task $j .{ }^{11}$

Our primary distance measure is thus the sum of the difference in average task usage between occupations over all the 19 tasks. Theoretically, the maximum distance between occupations is given if two occupations use complementary skill sets. For example, if all workers in occupation A use task 1-10 and none of the others, while in occupation B all workers perform only tasks 11-19. We normalize the measure to vary between 0 and 1 by dividing by the total number of tasks. The mean observed distance between occupations in the data is 0.053 with a standard deviation of 0.025 .

To account for changes in task usage over time, we calculated the distance measures separately for each wave. For the years 1975-1982, we use the measures from the 1979 cross-section, for 1983-1988 the task measures from the 1985 wave; for the years 1989-1994, we use the measures based on the 1991/2 wave; and the 1997/8 wave for the years 1995-2001. While there have been changes over time in the distance measures, they are with 0.7 highly correlated. Our results are robust to assigning different time windows to the measures. ${ }^{12}$

Table 1 lists at the top the three most similar and most distant pairs of occupations. The most distant move observed in the data is between a banker and a metal processor, unskilled worker or assembler. The occupations most similar in their task requirements are carpenter, a bricklayer or mason and a joiner or cabinet maker.

\footnotetext{
${ }^{11}$ Alternatively, $q_{j o}$ in (5) can be computed as follows. Let $D_{j i}$ be a dummy variable which is equal to 1 if individual $i$ performs task $j$. Each observation may then be weighted by the number of tasks reported by the individual, i.e. $q_{j o}=$ $\sum_{i \in o} \frac{D_{j i}}{\left(\sum_{j=1}^{J} D_{j i}\right)}$. The correlation between these two measures is over 0.95 , and both measures lead to very similar results.

${ }^{12}$ Since our data cover nearly three decades, it is not surprising that there are shifts in the composition of tasks used in occupations. In particular, we observe that the usage of analytical and to a lesser extent interactive tasks has increased in the 1990s. Similar results have been documented by Autor et al. (2003) for the United States and Spitz (2006) for West Germany using the same task data. Two-thirds of the overall increase in the demand for analytical tasks occurs within occupations and only one-third between (i.e. occupations with a higher demand for analytical skills grow relative to others). As a result, the average distance between occupations declined somewhat in the late 1990s making occupations more similar.
} 
The bottom panel in Table 1 shows the three most common occupational moves observed in the data for each education group. For the low-skilled, the most occupational moves are observed in and out of the occupation as a store and warehouse keeper. For individuals with a vocational degree, popular moves are from an office clerk to being employed as sales personnel or from working as an electrician to being a chemist or physicist. For the high-skilled, we observe many moves into and out of entrepreneurship and in and out of engineering.

The distance measure just described is one way of combining the information on task usage into a one-dimensional index. We construct two alternative distance measures to check the robustness of our results. Our second measure accounts for the fact that some of the nineteen tasks are more similar than others. ${ }^{13}$ Using the same formula as in (5), the measure calculates the average difference in task usage for the three aggregate task categories, analytical, manual, and interactive. As before, we normalize the measure to lie between zero and one by dividing by the number of tasks. The most distant moves for this second measure are between a banker and an unskilled worker and an unskilled construction worker, while the most similar occupations are between a joiner/cabinet maker and a plumber.

The third measure we calculate is the angular separation or uncentered correlation between two vectors. This distance measure has been used extensively in the innovation literature to calculate potential spillover effects from R\&D between firms with similar technologies (see for example, Jaffe, 1986). ${ }^{14}$ The measure also varies from 0 to 1 . The more two occupations overlap in their skill requirements, the closer the measure is to 0 . The mean distance with this measure in our data is 0.24 with a standard deviation of 0.22 . The most similar occupational moves for this measure are between occupations in processing (wood processing, paper processing, chemical processing). The most distant moves are between a banker

\footnotetext{
${ }^{13}$ Our main measure treats all tasks symmetrically and thus ignores that some tasks are more similar than others. To see this, suppose that workers in occupation A mostly clean, while workers in occupation B mostly repair machines. Workers in occupation $\mathrm{C}$ predominantly teach. It may be argued that the two tasks 'cleaning' and 'repairing' are more similar than the two tasks 'cleaning' (or 'repairing') and 'teaching'.

${ }^{14}$ The measure is calculated as

$$
\text { AngSep }{ }_{o o^{\prime}}=F_{o} F_{o^{\prime}}^{\prime} /\left[\left(F_{o} F_{o^{\prime}}\right)\left(F_{o o^{\prime}}\right)\right]^{1 / 2}
$$

where $F_{o}$ contains the fraction of workers using a task in occupation $o$ and $F_{o^{\prime}}$ is defined analogously. The measure varies from 0 to 1 . In order to make it comparable to our main distance measure, we rescaled it such that the two most distant occupations have a value of 1 (their vectors of tasks are orthogonal).
} 
and an unskilled construction worker.

The correlation between our three measures is with 0.68 (measures 1 and 2), 0.48 (measures 1 and 3) and 0.46 (measures 2 and 3) reasonably high. The results we present in the reminder of the paper are based on the first measure, which uses all nineteen tasks. Results based on the alternative distance measures are very similar and available from the authors on request.

\subsection{The German Employee Panel}

Our second data set is a two percent sample of administrative social security records in Germany from 1975 to 2001 with more than two million observations. The data has at least three advantages over household surveys commonly used in the literature to study mobility in the United States. First, its

administrative nature ensures that we observe the exact date of a job change and the wage associated with each job. Second, measurement error in earnings and occupational titles are much less of a problem than in typical survey data as misreporting is subject to severe penalties. Finally, occupational titles are consistent across firms as they form the basis for wage bargaining between unions and employers.

The data is representative of all individuals covered by the social security system, roughly 80 percent of the German workforce. It excludes the self-employed, civil servants, and individuals currently doing their compulsory military service. As in many administrative data sets, our data is right-censored at the highest level of earnings that are subject to social security contributions. Top-coding is about one percent for unskilled workers and those with an apprenticeship, but reaches almost 25 percent for university graduates.

We restrict our sample to men who entered the labor market in or after 1975. This allows us to construct precise measures of actual experience, firm and occupation tenure. Since the level and structure of wages differs substantially between East and West Germany, we drop all workers who were employed at least once in East Germany. Finally, we exclude all those working in agriculture.

Table 2 reports summary statistics of the main variables. In our sample, about 16 percent are low- 
skilled workers with no vocational degree. The largest fraction (68.3 percent) are medium-skilled workers with a vocational degree (apprenticeship). The remaining 15.4 percent are high-skilled workers with a tertiary degree from a technical college or university.

Wages are measured per day and deflated to 1995 German Marks. For medium-skilled workers, the median daily wage in our sample is $135 \mathrm{DM}$ or $\$ 85$ at 1995 prices. Median wages are about 15 percent lower for the low-skilled and 51 percent higher for the high skilled.

Our experience and tenure variables are measured in years, and exclude periods of unemployment and apprenticeship training. Actual experience is highest for low-skilled workers as they enter the labor market at a younger age (5.8 years versus 5.6 and 5.2 years for medium- and high-skilled workers respectively). The average time a medium skilled worker spends in the same occupation is 3.87 years, while the average tenure in a firm is with 2.79 years about one year lower. The values of task tenure lie with 5.19 for the low-skilled, 5.53 years for the medium- and 5.33 years for the high-skilled between those for actual experience and occupation tenure.

\subsection{Occupational Mobility}

Occupational mobility is an important feature of labor market careers in Germany. On average, annual mobility rates are 12.4 percent for our 64 two-digit occupations compared to 18.8 percent of job changers between firms. ${ }^{15}$ As Table 2 shows, occupational mobility is higher for the low-skilled (18.6 percent) and lowest for the high-skilled (10.9 percent). The same is true for firm mobility (23.6 percent and 18.0 percent for the low- and high-skilled respectively).

To see how occupational mobility changes with time in the labor market, the top panel of Figure 1a plots quarterly mobility rates over the first ten years in the labor market, separately by education group. Occupational mobility rates are very high in the first year (particularly in the first quarter) of a career, and highest for the low-skilled.

\footnotetext{
${ }^{15}$ We define the annual mobility rate as the probability that a worker switches occupations or firms at least once in a year. This provides a lower bound to occupational mobility since we do not account for multiple occupational moves within a year.
} 
For comparison, the Figure 1b shows mobility across firms. While firm mobility is somewhat higher throughout, it exhibits a very similar decline with time in the labor market. For example, in the first quarter after labor market entry, 22 percent of all low-skilled switch their occupation, while 25 percent switch firms. Ten years into the labor market, the quarterly firm and occupation quit rate drop to 4 percent and 2 percent, respectively. We now turn to a more detailed analysis of the patterns of mobility observed in the data.

\section{Patterns in Occupational Mobility and Wages}

This section uses the sample of occupational movers to demonstrate that skills are partially transferable across occupations. Section 4.1 study mobility behavior, while Section 4.2 analyzes wages before and after an occupational move.

\subsection{Occupational Moves are Similar}

Our framework predicts that workers are more likely to move to occupations with similar tasks requirements. To test this hypothesis, we compare the distance of observed moves to the distribution of occupational moves we would observe if mobility was purely random. We compute the distribution under random mobility by assuming that the decision to move to a particular occupation is solely determined by its relative size. For example, if occupation A employs twice as many workers as occupation B, the probability that a worker joins occupation A would then be twice as high as the probability that he joins occupation B.

Observed moves are calculated as the percentage of moves for each value of the distance measure. To compare this to expected distance under random mobility, we calculate the fraction of individuals leaving an occupation that would end up in any of the 63 occupations in proportion to their relative size. Each random source-target occupation combination is then multiplied with the appropriate distance measure. The way we calculate random mobility ensures that we account for shifts in the occupational structure 
over time, i.e. the fact that some occupations have increasing or decreasing employment shares.

Figure 2 plots the density of the distance measure under observed and random mobility. The horizontal axis is the distance measure where larger values are associated with movements to more distant occupations. The distribution of the distance measure under observed mobility is more skewed to the right than the distribution under random mobility. Therefore, observed moves are more similar than we would expect under random mobility. The two distributions are statistically different at the 1 percent level based on a Kolmogoroff-Smirnov test.

To allow a more detailed comparison, Table 3 compares selected moments of the distribution of our distance measure under observed and random mobility. The observed mean is much lower than what we would expect under random mobility. The same is true for the 10th, 25th, 50th, 75th and 90th percentile of the distance distribution. Both Table 3 and Figure 2 demonstrate that individuals are more likely to move to similar occupations in their career. This speaks against the assumption of standard search models that workers' past occupation has no impact on the type of occupation chosen.

If individuals accumulate task-specific human capital over time, we would also expect that distant moves occur early in the labor market career, and moves become increasingly similar with time in the labor market. Table 4 provides empirical support for these implications. It shows the results from a linear regression where the dependent variable is the distance of an observed move separately by education group. Column (1) controls for experience and experience squared and year and occupation dummies. For all education groups, the distance of an occupational move declines with time spent in the labor market though at a decreasing rate. The declining effect is strongest for the high-skilled, who also make more similar moves on average (see last row). For the high-skilled, 10 years in the labor market decrease the distance of a move by 0.014 or about 60 percent of the standard deviation. For the medium-skilled, the decline is only about 0.004 or 15 percent of a standard deviation.

Column (2) adds the time spent in the last occupation, while column (3) reports the results from a fixed-effects estimator to account for heterogeneity in mobility behavior across individuals. More time 
spent in the previous occupation decreases the distance of an occupational move in addition to labor market experience. The within estimator shows that occupational moves become more similar even for the same individual. The results are therefore not driven differences between low- and high experience workers. In fact, the decline in the distance becomes even more pronounced for all education groups in the fixed effects estimation.

Table 4 imposed a quadratic relationship between actual labor market experience and the distance of moves. In Figure 3, we relax this restriction. The figure displays the average distance of a move by actual experience, separately for the three education groups. The average distance is obtained from a least-squares regression of the distance on dummies for actual experience as well as occupation and year dummies, similar to Column (1) in Table 3. The figure shows that occupational moves become more similar at all experience levels and for all education groups, but particularly so for the high skilled. The decline between the first and 15th year of actual labor market experience is statistically significant at the 1 percent level.

In sum, individuals are more likely to move to occupations in which similar tasks are performed as in their source occupation, particularly so later in their career. Our framework proposes a simple explanation for this pattern. The basic mechanism is that human capital is more transferable between occupations with similar skill requirements.

\subsection{Wages in the Current Occupation depend on the Distance of Move}

If individuals move to more similar occupations because skills are more transferable, we would expect the wage at the source occupation to be a better predictor for the wage at the target occupation. Table 5 reports estimates from a wage regression, where the dependent variable is the log daily wage. All specifications include experience and experience squared as well as year and occupation dummies. Results are reported separately by education. As a benchmark for comparison, the first specification (column (1)) estimates the correlation of wages for occupational stayers. Wages in the same job are highly correlated 
over time with the correlation being strongest for university graduates. ${ }^{16}$

In the next specification, we restrict the sample to occupational movers who start out with zero occupational tenure (column (2)). For all education groups, the correlation of wages is lower among occupational movers than among occupational stayers. Specification 3 analyzes whether the impact of wages in the source occupation on wages in the target occupation varies with the distance of the occupational move. We add the distance of the move as well as the distance interacted with the wage at the source occupation as additional regressors. Indeed, the predictive power of the wage at the source occupation is larger for movers to similar occupations. Interestingly, the difference in the correlation is strongest for the high-skilled workers, i.e. the group that is also most likely to move to similar occupations. For this education group, our estimates imply that the impact of the wage at the source occupation on the wage at the target occupation is $0.368(0.372-2.092 \times 0.002)$ for the most similar move, and 0.250 $(0.372-2.092 \times 0.058)$ for the median move.

As a second test of skill transferability, we estimate whether tenure in the previous occupation matters for wages in the new occupation. In Column (1) of Table 6, we regress wages at the new occupation on occupational tenure at the previous occupation and the same controls as in Table 5. Past occupational tenure positively affects wages at the new occupation. This result is consistent with previous evidence that post-displacement wages depend positively on tenure in the pre-displacement job (e.g. Kletzer, 1989). Column (2) adds the distance measure interacted with past occupational tenure as controls. As expected, the predictive power of past occupational tenure is stronger if source and target occupations are similar. In line with our previous results, the impact of past occupational tenure declines more sharply with distance for university graduates. For this education group, the impact of past occupational tenure is $0.031(0.032-0.527 \times 0.002)$ for the most similar move, and $0.002(0.032-0.527 \times 0.058)$ for the median move.

To relax the linearity assumption, Figure 4a provides a nonparametric analysis of the correlation of

\footnotetext{
${ }^{16}$ For university graduates, we estimate censored wage regressions and drop observations for which the wage at the source occupation is censored. Due to its low incidence, we ignore censoring for the low- and medium-skilled.
} 
wages across occupations as a function of their distance. The x-axis shows the distance with one being the most similar occupational moves and 10 the most distant ones, while the y-axis reports the coefficient on the wage in the source occupation for each of the 10 categories. The coefficient is obtained form a tobit regression that controls for actual experience, actual experience squared, year dummies, the wage at the source occupation, 9 dummies for the distance of the move and the 9 dummies interacted with the wage at the source occupation (see column (3) in Table 4).

Three things are noteworthy: first, the figure highlights that wages at the source occupation have a stronger explanatory power for the wage at the target occupation if the source and the target occupation have similar skill requirements. Second and in line with our results on mobility and wages, the decline is strongest for the high-skilled. For this education group, the partial correlation coefficient between wages in the source and target occupation drops from 35 percent for the most similar move to around 19 percent for the most distant move; this drop is statistically significant at a one percent level. Third, the largest decline occurs from the first category (very similar moves) up to the 6th category. This pattern holds for all education groups.

Figure $4 \mathrm{~b}$ provides a similar analysis for past occupational tenure. The y-axis are now the coefficients on the 9 distance measure dummies from a tobit regression that also controls for actual experience, actual experience squared and year dummies. The correlation between past occupational tenure and wages in the new occupations is declining roughly linearly with the distance of the move. As before, the declining pattern is strongest for the high-skilled, particularly for very distant occupational moves.

We have performed a number of robustness checks. First, results for the other two distance measure are very similar. Second, our sample of movers contains both occupational switches between firms as well as within the same firm. The latter account for roughly 10 percent of all occupational movers. If some skills are tied to a firm, internal movers would have more portable skills than firm switchers. We therefore reestimated our specifications in Table 3 to 5 using only external movers. The results exhibit the same patterns in mobility and wages we observe for the whole sample of movers. 
Finally, our original sample of movers contains everybody switching occupations irrespective of the duration of intermediate un- or nonemployment spells. To the extent that those remaining out of employment for an extended period of time are different from for example job-to-job movers, our results might not be valid for those with high attachments to the labor market. To account for this, we reestimated the results only for the sample of workers with intermediate un- or nonemployment spells of less than a year. Again, this does not change our results on mobility and wages.

\subsection{Can these Patterns be Explained by Unobserved Heterogeneity?}

The strong patterns in mobility and wages reported in the last section support our view that specific human capital accumulated in the labor market is portable across occupations. This section discusses whether our findings could possibly be rationalized by individual heterogeneity.

Note first that all results presented so far are based on a sample of occupational movers. The patterns in mobility and wages can therefore not be accounted for by a simple mover-stayer model, where movers have a higher probability of leaving a job and therefore lower productivity because of less investment in specific skills. To the extent that movers differ from stayers in terms of observable and unobservable characteristics, this sample restriction reduces selection bias.

While focusing on the sample of movers reduces the selection problem, other sources of unobserved heterogeneity could bias our results. First, one might argue that the similar moves in the data are voluntary transitions, while distant moves occur because of layoffs from the previous job. If the distance of occupational move is correlated with workers' productivity on the job, this is consistent with the finding that wages are more highly correlated across similar occupations. It would also explain why past occupational tenure has a higher return in a similar occupation. However, the distinction between voluntary and involuntary movers does not explain why voluntary movers move to similar occupations in the first place.

One way to assess this alternative story is to see whether our results differ between job-to-job and 
job-to-unemployment transitions. Job-to-job changes are more likely to be voluntary, while moves into registered unemployment are more likely to be involuntary. We find that patterns in occupational mobility are very similar for the two types of moves. This results makes it unlikely that voluntary and involuntary occupational moves are responsible for our findings.

Second, suppose that the sample of movers differs in their taste for particular tasks. Some individuals prefer research over negotiating, while other prefer negotiating over managing personnel etc. Taste heterogeneity can explain why we see similar moves in the data. If individuals choose their occupations based on earnings and preferences for tasks, individuals would want to move to occupations with similar task requirements. However, a story based on taste heterogeneity alone cannot explain why wages are more strongly correlated between similar occupations. If there are compensating wage differentials, we would actually expect the opposite: individuals would be willing to accept lower wages for a move to an occupation with their preferred task requirements.

Finally, suppose that high ability workers are less likely to switch occupations. This could account for the fact that the time spent in the last occupation has a positive effect on wages in the current occupation, as past occupational tenure would act as a proxy for unobserved ability in the wage regression (see Table 5). However, unobserved ability per se cannot explain why the effect of past occupational tenure should vary with the distance of the move or why individuals move to similar occupations at all.

Our discussion highlights that a simple story of unobserved heterogeneity cannot account for all of the results presented above. It is however also clear that occupational movers are not a random sample of the population of workers. ${ }^{17}$ Individuals choose to switch occupations and they can also choose the distance of their occupational move. In our theoretical framework, a worker only moves to a distant occupation if the loss in human capital is compensated by higher (occupation- or firm-specific) match quality. This leads us to overstate the transferability of skills to distant occupations in Figure 4a and 4b. In the next section, we outline our strategy to estimate the quantitative importance of task-specific human capital

\footnotetext{
${ }^{17}$ The importance of selection can be clearly seen in Table 4. Including individual fixed effects in the estimation (column (3)) makes the negative effect of experience (occupational tenure) on the distance of an occupational move stronger (weaker) compared to the specification without fixed effects (column (2)).
} 
for individual wage growth relative to other common measures of specific human capital.

\section{Task-Specific Human Capital and Individual Wage Growth}

\subsection{Empirical Framework}

To estimate the contribution of task-specific human capital to individual wage growth, we start from the following log-wage regression (see equation (3) in Section 2):

$$
\ln w_{i j o t}=P_{o}+\gamma_{1} E_{i t}+\gamma_{2} O T_{i o t}+\gamma_{3} T T_{i o t}+\gamma_{4} F T_{i j t}+u_{i j o t}
$$

where $E_{i t}$ denotes actual experience, $T T_{i o t}$ task tenure, $O T_{i o t}$ occupation tenure, and $F T_{i j t}$ firm tenure. The unobserved (for the econometrician) error term $u_{i j o t}$ is defined by:

$$
u_{i j o t}=a_{i}+o_{i o t}+f_{i j t}+\varepsilon_{i j o t} .
$$

The unobserved wage component consists of unobserved worker ability $\left(a_{i}\right)$, the task-specific match in an occupation $\left(o_{i o t}=\beta_{o} T_{i t}^{A}+\left(1-\beta_{o}\right) T_{i t}^{M}\right)$, a firm-specific match $\left(f_{i j t}\right)$, and a random component due to measurement error in wages or market-wide fluctuations $\left(\varepsilon_{i j o t}\right)$. We assume that $\varepsilon_{i j o t}$ is i.i.d. and orthogonal to the regressors and other components of $u_{i j o t}$.

Since the focus of this paper is on the importance of task-specific human capital, our main goal thus is to get consistent estimates for $\gamma_{1}$ to $\gamma_{3}$, i.e. the returns to general, occupation-, task-specific human capital. The problem with estimating wage regression (6) by least squares is that workers choose whether to switch firms and occupations, and whether to move to a similar or distant occupation. Moreover, actual experience may be correlated with unobserved worker ability if more able workers are less likely to become unemployed. Both will lead to a correlation between our regressors and the error term in (7).

To see how selection affects least squares estimates, define the following auxiliary regressions for 
workers who have just switched firms $\left(F T_{i j t}=0\right)$ :

$$
\begin{aligned}
a_{i} & =b_{a} E_{i t}+c_{a} O T_{i o t}+d_{a} T T_{i o t}+\epsilon_{i j o t}^{a}, \\
o_{i o t} & =b_{o} E_{i t}+c_{o} O T_{i o t}+d_{o} T T_{i o t}+\epsilon_{i j o t}^{T} \\
f_{i j t} & =b_{f} E_{i t}+c_{f} O T_{i o t}+d_{f} T T_{i o t}+\epsilon_{i j o t}^{f}
\end{aligned}
$$

Suppose we estimate wage regression in (6) by least squares, using a sample of firm switchers (i.e. $\left.F T_{i j t}=0\right)$. This identifies:

$$
\begin{aligned}
& \widehat{\gamma}_{1}=\gamma_{1}+b_{a}+b_{o}+b_{f}, \\
& \widehat{\gamma}_{2}=\gamma_{2}+c_{a}+c_{o}+c_{f}, \\
& \widehat{\gamma}_{3}=\gamma_{3}+d_{a}+d_{o}+d_{f} .
\end{aligned}
$$

First, consider the return to task-specific human capital, $\gamma_{3}$. In Table B.3 in Appendix B, we provide evidence in favor of a negative selection of movers to distant occupations. That is, workers who move to a distant occupation earn lower wages in their source occupation than workers who move to a similar occupation. A possible interpretation of this finding is that workers' general ability reduces his probability to switch to a distant occupation. This argument implies $d_{a}>0$ and thus an upward bias in the return to task-specific human capital. However, $\gamma_{3}$ may also be downward biased. In particular, workers may choose to work in a distant occupation because a high firm match compensates them for the loss in task-specific human capital; hence, $d_{f}<0$. In contrast, we would not expect a strong correlation between task tenure and the occupational match $\left(d_{o}=0\right)$ - as it is the relative task-specific productivity that determine occupational choice (see Section 2).

What about the return to occupation-specific human capital, $\gamma_{2}$ ? If more able workers are less likely to switch occupations, then $c_{a}>0$, implying an upward bias in $\gamma_{2} \cdot{ }^{18}$ It is often argued that workers

\footnotetext{
${ }^{18}$ Table B.3 in Appendix B shows that occupational movers earn about 10 percent lower wages than occupational stayers.
} 
with longer occupational tenure (conditional on experience) are better matched with their occupation. However, as workers may switch occupations because of a better occupational match, workers with low levels of occupational tenure may be particularly well matched. Hence, $c_{o} \gtrless 0$. Finally, if workers switch occupations because of a high firm-specific match, $c_{f}<0$.

Finally, the return to general human capital is likely to be upward biased (i.e. $\widehat{\gamma}_{1}>\gamma_{1}$ ). With time in the labor market, workers find firms and occupations that best use their task productivity through onthe-job search, i.e. $b_{o}>0$ and $b_{f}>0$. Moreover, more able workers are less likely to become unemployed. Hence, we expect the unconditional correlation between actual experience and the worker ability $a_{i}$ to be positive. However, conditional on task and occupation tenure, the partial correlation between ability and experience may be negative (i.e. $b_{a}<0$ ) if more able workers are less likely to switch occupations or move to distant occupations. ${ }^{19}$

This discussion shows that it is not in general possible to sign the bias in least squares estimates of the returns to general, occupation-specific, and task-specific human capital. To address this problem, our estimation strategy proceeds in several steps. We first present estimates from least squares wage regressions including and excluding our measure of task-specific human capital. While this does not deal with the selection problem, the comparison of the estimates of the returns to general and occupationspecific human capital, conditional and unconditional on task-specific human capital, is informative of the relative importance of task-specific skills.

Second, we restrict our sample to displaced workers who were exogenously displaced from their job due to plant closure (see Gibbons and Katz, 1991; Neal, 1995 and Dustmann and Meghir, 2005). ${ }^{20}$ Displaced workers differ from voluntary firm switchers because they are willing to accept a new job if its value exceeds the value of unemployment, as opposed to the value of the old job. They thus lose their 'search capital' and have to search from scratch for a good firm or occupation match. This reduces the correlation This is consistent with occupational movers being less able than occupational stayers.

${ }^{19}$ To see this, suppose for worker $1, T T=5, O T=5$, and $E=5$. For worker $2, T T=5, O T=5$, and $E=10$. Hence, worker 1 never switched occupations, while worker 2 did. Worker 2 may be the less able worker; hence $b_{a}<0$.

${ }^{20}$ Dustmann and Meghir (2005) provide evidence that the assumption of plant closure as an exogenous job loss is reasonable in the German context. 
between experience and firm and occupation match quality (i.e. $b_{o}$ and $b_{f}$ ), and thus any upward bias in the returns to experience.

However, least squares estimates for the return to occupation- and task-specific human capital may be biased even for displaced workers, as workers choose their post-displacement occupation. Recall from our discussion above that least squares estimates for the return to task-specific human capital are upward biased if more able workers are less likely to move to distant occupations. In a third step, we eliminate this source of bias by estimating first difference regressions, using a sample of firm switchers as well as of workers displaced from their old job because of plant closure. We interpret these estimates as a lower bound for the true return to task- and occupation-specific human capital, for the following reason. Workers are only willing to switch occupations, or move to a distant occupation, if the gain in the occupation- or firm-specific match compensates them for the loss in their specific human capital. Workers who choose to switch occupations, or choose to move to a distant occupation, thus have less to lose than a randomly selected worker. Due to wage censoring, we cannot estimate first difference models for university graduates. Here, we use Honoré's trimming estimator (1992) for the censored regression (Type 1 tobit model) with fixed effects. Since the estimator is semiparametric, no functional form assumption on the error term is required. However, we do require pairwise exchangeability of the error terms conditional on the included regressors. ${ }^{21}$

Our final strategy uses instrumental variables for the sample of exogenously displaced workers. To deal with a possible correlation between ability and actual experience, we instrument actual experience with potential experience. For occupational and task tenure, we require instruments that affect the decision to switch occupations and the distance of an occupational move, but do not have an independent effect on individual wages. Our instruments exploit variation in job opportunities across regions and over time. We define a region at the district (Kreis) level, and include all surrounding districts. This roughly

\footnotetext{
${ }^{21}$ More specifically, conditional pairwise exchangeability of the sequence $\left\{\varepsilon_{t}\right\}_{t=1}^{T}$ requires that for any $t \neq s$, $\left(\varepsilon_{t}, \varepsilon_{s}\right)$ is identically distributed as $\left(\varepsilon_{s}, \varepsilon_{t}\right)$ conditional on the included regressors. That is, we require $\operatorname{that} \operatorname{Pr}\left(\varepsilon_{t}<c, \varepsilon_{s}<d \mid z\right)=$ $\operatorname{Pr}\left(\varepsilon_{s}<c, \varepsilon_{t}<d \mid z\right)$. For example, this is satisfied if $\varepsilon_{t}$ is iid, but also under weaker assumptions on the error structure (see Honoré, 1992 for details).
} 
corresponds to a 50 mile radius from workers' residence. The idea is that following plant closure, workers predominantly search for a new job locally, in their region of residence. To instrument for tenure in an occupation, we use the number of workers leaving (joining) an occupation relative to all occupational leavers (joiners) as well as the overall size of the occupation. To instrument for the distance of an occupational move, we exploit information on the average distance of an occupation to all others in the same region. For each year $t$, occupation $o$ and region $r$, we compute the average distance as follows:

$$
A D_{o r t}=\sum_{o^{\prime} \neq o}^{64} \operatorname{Prop}_{o^{\prime} r t} \cdot D i s_{o o^{\prime} t} \quad \forall o
$$

where $D i s_{o o^{\prime} t}$ denotes the distance between occupation $o$ and $o$. We calculate this measure both for all jobs (so Prop $_{o^{\prime} r t}$ denotes the fraction of workers in occupation $o^{\prime}$ ) and for those leaving their occupation (then Prop $_{o^{\prime} r t}$ denotes the fraction of all occupational switchers in occupation $o^{\prime}$ ). We expect workers to be less likely to move to a distant occupation in a region in which there are more job openings in a similar occupation. We also include maximum distance in the local labor market and the distance to the 10 percent least similar occupations as instruments.

Since our specifications include occupation, region and time dummies, the variation we exploit is changes in occupational structure and job movements over time within the same region. The advantage of this approach is that we avoid a correlation any individual-level instruments could have with the error term in (7). The identifying assumption of our instrument set is that conditional on occupation, region and time dummies, the number of workers who join and leave an occupation as well as the average distance of an occupation have no independent impact on individual wages. This condition will be satisfied if one of two conditions hold: first, workers search only locally for a new job. For the low and medium educated, regional mobility following a job loss due to plant closure is with 16 percent relatively low. For university graduates, in contrast, regional mobility is substantial (30.2 percent). Alternatively, we require that there is no net flow out of or into a particular local labor market. Or, if there is a net outflow or inflow, it does 
not affect wages conditional on our regressors.

\subsection{Empirical Results}

Table 7 reports results from least squares regressions of equation (6). Due to wage censoring, we estimate censored regressions for university graduates. The first specification (column (1) and (2)) uses the whole sample of workers. Column (1) displays results from a wage regression that ignores task-specific human capital, while column (2) includes task tenure as an additional regressor. If human capital is indeed partially transferable across occupations, we expect the return to occupational tenure and possibly experience to decline once we include a measure of task human capital.

There are several noteworthy patterns. Returns to task tenure are sizeable and exceed those of occupational tenure for all education groups. For the high-skilled, task-specific human capital is the most important source of wage growth. Once we include task tenure, the return to occupational tenure declines by 30 to $50 \%$ for the two lower educated groups, and even becomes negative for the high-skilled. In addition, returns to experience decline by about 30 percent for the low- and medium-skilled and by 40 percent for the high-skilled. Finally, the inclusion of task-specific tenure has little impact on the return to firm tenure for either education group.

The second specification (columns (3) and (4)) report results based on a sample of workers starting at new firm (i.e. to workers with firm tenure equal to zero). Compared to the full sample, the return to general experience is lower while the returns to occupation and task tenure are higher for all education groups. ${ }^{22}$ Task tenure remains an important source of individual wage growth.

The third specification (columns (5) to (7)) reports the results from our sample of workers displaced from their old firm because of plant closure. Column (5) excludes task tenure, column (6) excludes occupation tenure, and column (7) includes both measures of human capital. In line with the idea that displaced workers lose their search capital, this specification yields slightly lower estimates for the return

\footnotetext{
${ }^{22}$ Results are almost identical if we further restrict the sample to firm and occupation movers (i.e. workers with firm and occupation tenure equal to zero).
} 
to experience. The overall patterns, however, remain unchanged. In particular, the return to task human capital exceeds that of occupation human capital for all education groups.

To account for the selection of workers into new occupations, Table 8 reports results from first difference (low and medium) and fixed effect (high) regressions, as well as instrumental variable estimates. For the low- and medium-skilled, columns (1) and (2) use a sample of firm switchers, while columns (3) and (4) are based on our sample of workers displaced because of plant closure. For the high-skilled, we use Honoré's trimming estimator (1992) for the censored regression (Type 1 tobit model) with fixed effects. Here, columns (1) and (2) refer to a sample of firm switchers. As discussed above, first difference and fixed effects estimates provide a lower bound to the true returns to occupational and task-specific human capital.

Consider first the low- and medium-skilled. First difference estimates for the return to task-specific human capital are smaller than the level estimates in Table 7, columns (3) to (7). This confirms our hypothesis that distant occupational movers are negatively selected in terms of ability. Note that the coefficient on task tenure exceeds that on occupation tenure, and the coefficient on occupation tenure declines if task tenure is included in the regression. Also note that in the first difference regression, the coefficient on (the change in) experience should not be interpreted as returns to general human capital accumulation, as they additionally reflect the change in the firm and occupation match quality. Turning to university graduates, accounting for time-invariant worker ability likewise reduces the return to task human capital. However, task-specific human capital remains the most important source of wage growth. Finally, we report our instrumental variable estimates for the displaced worker sample in columns (5) to (7) of Table 8. The first stage of our instrumental variable estimator is reported in Table B.4 in the Appendix. ${ }^{23}$ The estimates and test statistics reported at the bottom of Table B4 suggest that

\footnotetext{
${ }^{23}$ The number of leavers or joiners in an occupation affects the decision to switch occupations in two ways. If large numbers are leaving an occupation, there are potentially a lot of job openings in that occupation. The fraction of leavers would then be positively correlated with occupational tenure. This is the case for the high skilled. However, a large number of leavers could also signal declining employment in that occupation. In this latter, we expect the fraction of leavers to be negatively correlated with occupational tenure, which fits the low-skilled estimates. A similar argument can be made for the fraction of those joining an occupation. Here, we find that a lot of jobs taken in an occupation encourages occupational mobility. The size of the occupation in contrast is positively correlated with the probability of remaining in the occupation and therefore occupational tenure.
} 
our instruments are weak. While the instruments affect our measures of specific skills (see the F-test of excluded instruments), they do have little independent variation on occupational tenure (occupational mobility) and task tenure (distance of occupational move). This is reflected in the low Shea's partial $R^{2}$ that accounts for multicollinearity between instruments.

The presence of weak instruments is not too surprising in our case. Our framework suggests that the decision to switch occupations and the distance of an occupational move are jointly determined by the amount of task- and occupation-specific skills as well as the occupational match. Furthermore, our instruments rely purely on variation in occupational structure and job movements within regions over time. With weak instruments, it is well known that instrumental variables are biased towards least squares estimates. We therefore use Fuller's k-estimator which is partially robust to weak instruments and has been shown to perform well in Monte Carlo simulations (see Stock et al., 2002). Since our instrument have little independent variation on occupational and task tenure, we also report results in which we only include and instrument for occupation tenure (column (5)), or only include and instrument for task tenure (column (6)).

The instrumental variable estimates exhibit a similar pattern to the least squares estimates for the same sample (columns (5) to (7) in Table 7). For all education groups, the return to task tenure is larger in magnitude than the least squares estimate. However, our instrumental variable estimates are noisy, and do not obtain statistical significance.

What do our estimates imply for the hypothetical wage loss of job displacement due to the loss of occupation- and task-specific skills? We base our calculation on the OLS estimates for the displaced sample (Table 7, columns (5) and (7)). We first assume that specific skills fully depreciate if a worker switches occupations (column (5)). Our alternative assumption is that skills are task-specific and therefore partially transferable across occupations (column (7)). We consider these numbers a lower bound to the true wage loss since our calculation does not include the loss in firm and task match quality.

According to our estimates, a low-skilled worker who spent 10 years at in his occupation would lose 
16.1 percent $(0.0161 * 10)$ of his wage if he switched occupations, and skills are purely occupation-specific. In contrast, if specific skills are partially transferable across, and the worker finds employment in similar occupation (e.g. in the 10th percentile of the distribution of moves), he loses only about 10.2 percent. If he makes a more distant move, e.g. the median distance in our sample, he would lose 17.7 percent ${ }^{24}$. The basic pattern holds for all education and experience groups: wage losses of displacement vary with the type of the occupational move after displacement.

Overall, our evidence suggests that task-specific human capital accumulation is an important source of individual wage growth. For the university graduates, task-specific human capital plays a much more important role than purely general or purely specific human capital. These results imply that standard wage regressions that ignore task-specific human capital are misspecified. We also provide evidence that the costs of displacement and job reallocation depend on the employment opportunities after displacement. Wage losses are lower if individuals find employment in an occupation with similar skill requirements.

\section{Conclusion}

How general is specific human capital? The evidence in this paper demonstrates that specific skills are more portable than previously considered. We show that workers are much more likely to move to similar occupations and that the distance of occupational moves declines sharply over the life-cycle. Furthermore, wages and occupation tenure at the source occupation have a stronger impact on current wages if workers switch to a similar occupation. Finally, the accumulation of task-specific human capital is an important source of wage growth, and exceeds that of occupation-specific human capital for all education groups.

Our results are consistent with the idea that workers can transfer specific human capital across occupations. They are however difficult to reconcile with a standard human capital model with either

\footnotetext{
${ }^{24}$ These numbers are computed as follows. According to column (7), a low-skilled worker who spent 10 years at his previous occupation loses $7.7 \%$ in terms of purely occupation-specific skills. If he moves to a similar occupation (i.e. 10th percenitle), he can transfer $90 \%$ of his task-specifi skills. In sum, he thus loses $0.077+0.1 * 10 * 0.0205=10.2 \%$. If instead he moves to a more distant occupation (e.g. median distance), he can transfer only $50 \%$ of his task-specific skills. He thus loses 0.077 $+0.5 * 10 * 0.0205=17.7 \%$.
} 
fully general or firm- (or occupation-) specific skills. Our findings also contradict undirected search models of turnover where the current occupation has no effect on future occupational choices, and skills are not transferable across occupations (e.g. Kambourov and Manovskii, 2002; Neal, 1999; Pavan, 2005).

Our findings on both mobility patterns and wage effects are strongest for the high-skilled, suggesting that task-specific skills are especially important for this education group. It is interesting to speculate why we observe this pattern. One explanation could be that formal education and task-specific human capital are complements in production. Complementarity implies that high-skilled workers accumulate more task human capital on the job which would account for the sharp decline in the distance of moves over the life cycle. It would also explain why wages in the previous occupation are less valuable in the new occupation and why returns to task human capital are higher than for other education groups.

We view the results on the importance of task human capital in Germany as a lower bound for the United States, as Germany's system of vocational training relies more on specific skills than for example a college education. The assumption of more general skills in the United States is at the heart of recent attempts to explain the productivity differential between the United States and Europe (Krueger and Kumar, 2004; Wasmer, 2005). Given comparable data to ours for the United States, the approach in this paper allows to test this assumption empirically.

Our framework and findings suggest several other avenues for future research. Our calculations show that job displacement costs are lower if one can find a job in an occupation with similar skill requirements. This result for example has important implications for targeting government sponsored training and active labor market programs. Another interesting question is how technological change and changes in the organization of production affect the types of skills accumulated on-the-job and mobility patterns. For example, has recent technological change made specific skills more or less transferable across jobs? And how do these changes affect specialization in the labor market? Our task data, combined with panel data on mobility and wages, provides a unique opportunity to address these questions. 


\section{References}

[1] Abraham, K. G., and H. S. Farber (1987), "Job Duration, Seniority, and Earnings," American Economic Review, 77, 278-97.

[2] Altonji, J. and R. Shakotko (1987), "Do Wages Rise with Job Seniority?," Review of Economic Studies, 54, 437-59.

[3] Altonji, J. and N. Williams (2005), "Do Wages Rise with Job Seniority? A Reassessment," Industrial and Labor Relations Review, 58, 370-97.

[4] Autor, D., R. Levy and R.J. Murnane (2003), "The Skill Content of Recent Technological Change: An Empirical Investigation", Quarterly Journal of Economics, 118, 1279-1333.

[5] Becker, G.S. (1964), Human Capital, University of Chicago Press.

[6] Ben-Porath, Y. (1967), "The Production of Human Capital and the Life-Cycle of Earnings," Journal of Political Economy, 75, 352-65.

[7] Borghans, L., B. ter Weel and B.A.Weinberg (2006), "Interpersonal Styles and Labor Market Outcomes, " mimeo, Maastricht University.

[8] DiNardo, J. and J.-S. Pischke (1997), "The Returns to Computer Use Revisited: Have Pencils Changed the Wage Structure Too?," Quarterly Journal of Economics, 112, 291-303.

[9] Dustmann, C. and C. Meghir (2005), "Wages, Experience and Seniority," Review of Economic Studies, $72,77-108$.

[10] Farber, H. (1999), "Mobility and Stability: The Dynamics of Job Change in Labor Markets," in: Handbook of Labor Economics, volume 3, edited by O. Ashenfelter and D Card, Elsevier Science.

[11] Flinn, C. (1986), "Wages and Job Mobility of Young Workers," Journal of Political Economy, 84, S88-S110.

[12] Gibbons, R. and L.F. Katz (1991): "Layoffs and Lemons," Journal of Labor Economics, 9, 351-80.

[13] Gibbons, R.; L.F. Katz; T. Lemieux and D. Parent (2005): "Comparative Advantage, Learning and Sectoral Wage Determination," Journal of Labor Economics, 23, 681-724.

[14] Heckman, J.J. and G. Sedlacek (1985), "Heterogeneity, Aggregation, and Market Wage Functions: An Empirical Model of Self-Selection in the Labor Market," Journal of Political Economy, 93: 1077-1125.

[15] Honoré, B. (1992), "Trimmed LAD and Least Squares Estimation of Truncated and Censored Regression Models with Fixed Effects," Econometrica, 60, 533-65.

[16] Ingram, B.F. and G. Neumann (2006), "The Return to Skill," Labour Economics, forthcoming.

[17] Jacobson, L., R. Lalonde and D. Sullivan (1993), "Earnings Losses of Displaced Workers," American Economic Review, 83, 685-709.

[18] Jaffe, A.B. (1986), "Technological Opportunity and Spillover of R\&D: Evidence from Firms' Patents, Profits, and Market Value," American Economic Review, 76, 984-1001.

[19] Jovanovic, B. (1979a), "Firm Specific Capital and Turnover," Journal of Political Economy, 87, 1246-60. 
[20] Jovanovic, B. (1979b), "Job Matching and the Theory of Turnover," Journal of Political Economy, 87, $972-90$.

[21] Kambourov, G. and I. Manovskii (2002), "Occupational Specificity of Human Capital," mimeo, University of Toronto.

[22] Kambourov, G. and I. Manovskii (2004), "Occupational Mobility and Wage Inequality," mimeo, University of Toronto.

[23] Kletzer, L. (1989), "Returns to Seniority after Permanent Job Loss," American Economic Review, $79,536-53$.

[24] Krueger, D. and K.B. Kumar (2004), "Skill-Specific rather than General Education: A Reason for US-Europe Growth Differences?," Journal of Economic Growth, 9, 167-207.

[25] Lazear, E.P. (2003), "Firm-Specific Human Capital: A Skill-Weights Approach," NBER Working Paper W9679.

[26] Malamud, O. (2005), "Breadth vs. Depth : The Effect of Academic Specialization on Labor Market Outcomes," Harris School Working Paper Series 05.17.

[27] McCall, B.P. (1990), "Occupational Matching: A Test of Sorts," Journal of Political Economy, 98: 45-69.

[28] Miller, R. (1984), "Job Matching and Occupational Choice," Journal of Political Economy, 92: 1086-1120

[29] Mincer, J. (1974), Schooling, Experience and Earnings, Columbia University Press.

[30] Murphy, K.M. (1986), "Specialization and Human Capital," Unpublished Dissertation, University of Chicago.

[31] Neal, D. (1995), "Industry-Specific Capital: Evidence from Displaced Workers," Journal of Labor Economics, 13: 653-77.

[32] Neal, D. (1999), "The Complexity of Job Mobility among Young Men," Journal of Labor Economics, 17: $237-61$.

[33] Parent, D. (2000), "Industry-Specific Capital and the Wage Profile: Evidence from the National Longitudinal Study of Income Dynamics," Journal of Labor Economics, 18: 306-23.

[34] Pavan, R. (2005), "Career Choice and Wage Growth," mimeo, University of Chicago.

[35] Poletaev, M. and C. Robinson (2004), "Human Capital and Skill Specificity," CBIC working paper, University of Western Ontario.

[36] Rosen, S. (1983), "Specialization and Human Capital," Journal of Labor Economics, 1, 43-49.

[37] Shaw, K. (1987), "Occupational Change, Employer Change, and the Transferability of Skills," Southern Economic Journal, 53: 702-19.

[38] Spitz-Oener, A. (2006), "Technical Change, Job Tasks, and Rising Educational Demands: Looking Outside the Wage Structure," Journal of Labor Economics, 24, 235-70.

[39] Stock, J.H.; J. Wright and M. Yoto (2002), "A Survey of Weak Instruments and Weak Identification in Generalized Method of Moments," Journal of Business and Economic Statistics, 20, 518-29. 
[40] Topel, R. (1991), "Specific Capital, Mobility and Wages: Wages Rise with Job Seniority," Journal of Political Economy, 99, 145-76.

[41] Topel, R. and M. Ward (1992), "Job Mobility and the Careers of Young Men," Quarterly Journal of Economics, 107, 439-80.

[42] Violante, G.L. (2002), "Technological Acceleration, Skill Transferability, and the Rise in Residual Inequality," Quarterly Journal of Economics, 117, 297-338.

[43] Wasmer, E. (2004), "General vs. Specific Skills in Labor Markets with Search Frictions and Firing Costs," American Economic Review, 96, 811-831.

\section{A Data Sources}

\section{A.1 Employee Sample (1975-2001)}

Our main data set is the Employee Sample, a 2 percent sample of all German social security records administered by the Institute for Employment Research from 1975 to 2001. The data contains an unusually in-depth set of background information for each individual, including age, education, gender, nationality, occupation, etc.

By law, employers are required to report the exact beginning and end of any employment relation of all new hires and employees leaving the firm which are subject to social security contributions. In addition, employers provide information about all their employees at the end of each year. We therefore know the exact date of employer changes and movements into and out of paid employment. ${ }^{25}$

The occupational categories of employees and apprentices in the social security records are highly accurate as the classification forms the basis of wage agreements between unions and employers' association. In the $2 \%$ sample, we have 130 occupations available. To make this classification comparable to the tasks performed in occupations from the BIBB data, we aggregated them further into 64 occupations at the 2-digit level.

Employers are not required to notify an occupational switch if the employee remains with the same firm, but we do know the employee's occupation at the end of each year. This leads us to underestimate occupational mobility relative to firm mobility. To see this, consider first a worker who switches firms on April 1st. For this worker, we observe two spells: the first from January 1st to March 31st and the second from April 1st to December 31st. Suppose that the individual works in occupation A in the first spell, and B in the second spell. For this worker, and firm switchers in general, it is reasonable to assume that he worked on January 1st at occupation A, and April at occupation B. He may have switched occupations once more between January and April, and between April and December. Next, consider a worker who stayed with the same employer for at least two years. For this worker, we observe two spells, both from January 1st to December 31st. Suppose that the first spell classifies the worker as in occupation A, while this spell classifies him as in occupation B. For this worker, it is reasonable to assume that on January

\footnotetext{
${ }^{25}$ Our employer identifier refers to the plant level. We are therefore able to track employer changes between plants within the same firm. Throughout the paper, we use the terms 'firms' and 'plants' interchangeably.
} 
1st he was working in occupation A, and on January first one year later in occupation B. He may have switched occupations more than once.

As in many administrative data sets, observations on wages are censored if they exceed the upper limit for social security contributions. Overall, around 4 percent of the observations have right-censored wages. Censoring is less than 2 percent for the low and medium skilled, but almost 25 percent among the high-skilled. Due to its low incidence, we ignore censoring for the low- and medium-skilled. ${ }^{26}$ For the high-skilled, we estimate tobit models whenever appropriate. After 1984, firms have to report wages inclusive of fringe benefits, which affects mostly the wages of high-skilled workers. To control for that and other aggregate shocks, we always include year effects in the estimation.

Sample restrictions In addition to the sample restrictions mentioned in the text, we dropped all spells in vocational training and those job spells that started prior to an apprenticeship or tertiary education. In addition, we excluded observations that were still in vocational training at the end of the sample period in 2001 or pursued more than one apprenticeship, that is were employed as an apprentice for more than 7 years. We also require a person to be below a certain age when we first observe them. This ensures that we can follow them from day one of their entry into the labor market. The age restriction is 19 if the individual has no high school degree (Abitur), 22 if the individual has a high school degree, but no higher degree, 28 if the individual graduated from a community college (Fachhochschule), and 30 if he graduated from university. Finally, we drop all observations we observe less than a year, with missing education or nationality, and observations with no valid wage or a daily wage below 20 DM during an employment spell.

\section{Variable definitions}

- Education: We distinguish three education levels: low-, medium-, and high-skilled. We define a worker to be high-skilled if at least one spell classifies him as a graduate from a university or technical college. (Fachhochschule). A worker is medium-skilled if he spent at least 450 days in apprenticeship training, and no spell classifies him as a college graduate. A worker is low-skilled if he spent less than 450 days in apprenticeship training and did not attend a technical college or university.

- Experience and tenure: All experience and tenure variables refer to the beginning of each spell. Time out of the labor force and time in unemployment as well time in apprenticeship training is not counted. There are some workers in our data sets who return to an occupation they have worked for in the past. When constructing occupation tenure, we ignore time out of an occupation when we calculate occupational tenure. That is, a worker who has worked in the same occupation without an interruption for three years and a worker who has worked in the same occupation for two years and then returns to that occupation for another year both have three years of occupational tenure. The same holds in the unlikely event that a worker returns to a firm he has worked for previously. Our results on occupational movers (Table 3 to 6) do not include these return movers. Our results are similar if return movers are included in the sample.

\footnotetext{
${ }^{26}$ For these education groups, results from a linear wage regression and a tobit model are almost identical.
} 
Table A1: Calculation of Task Tenure

\begin{tabular}{lccccc}
\hline \hline & OccTen, end & OccTen, beg. & Rel. Distance & TaskTen, end & TaskTen, beg. \\
\hline occupation A & 1 & 0 & & 1 & 0 \\
occupation B & 1 & 0 & 0.5 & 1.5 & 0.5 \\
occupation C & 1 & 0 & $0.2(\mathrm{~A}), 0.8(\mathrm{C})$ & 2 & 1 \\
\hline \hline
\end{tabular}

Note: Relative distance: $\frac{\text { max.distance-distance }}{\text { max.distance }}$.

- Task human capital: Task tenure increases by the duration of the spell if the worker stays with the occupation. If he switches occupations, task tenure depends on the relative distance of the move. We normalize the transferability of skills to the most distant occupation to zero. We define the relative distance between two occupations $\mathrm{A}$ and $\mathrm{B}$ as the difference between the maximum distance in our data (across all occupation pairs) and the distance between occupations $\mathrm{A}$ and $\mathrm{B}$, divided by the maximum distance. As an example, consider a worker who works one year for occupation A, then switches to occupation B, and after one year switches to occupation C. Suppose the relative distance between occupation $\mathrm{A}$ and $\mathrm{B}, \mathrm{A}$ and $\mathrm{C}$, and $\mathrm{B}$ and $\mathrm{C}$ is $0.5,0.2$ and 0.8 , respectively. Task tenure at the end of the spell is then computed as $1,1.5(0.5 \cdot 1+1)$, and $2(0.2 \cdot 1+0.8 \cdot 1+1)$ (see Table A1).

- Plant closure: Our data set contains information on the year in which a plant employed at least one worker. We use this information to identify workers who left their firm due to plant closure. According to our main definition, a worker is displaced from his firm due to plant closure if he left the firm in the year or one year before the firm closed down. As a robustness check, we have repeated the analysis restricting the sample to workers who have left the firm in the year or one or two year before the firm closed down. The former definition has the advantage that it is likely to include less workers who have left the firm voluntarily, for reasons other than plant closure. However, it has the disadvantage that it may exclude workers that leave the firm prior to plant closure, anticipating that the firm may shut down in the future. Both definitions give very similar results.

- Instruments: Our instruments for occupation and task tenure exploit regional and time variation in the occupation structure. We define a region as the individual's county (Kreis) of residence as well as all the neighboring counties, corresponding roughly to a 50 mile radius from the individual's home. A time period refers to a year. The instruments for occupational tenure are: fraction leaving occupation $o$ in region $r$ at time $t$ (i.e. employed in $r$ and $o$ in $t$, but not in $t+1$ ); fraction joining occupation $o$ in region $r$ at time $t$ (i.e. employed in $r$ and $o$ in $t+1$, but not in $t$ ); size of the occupation (fraction employed in occupation $o$ in region $r$ at time $t$. For task tenure, we use the following instruments: average distance of occupation $o$ to all other occupations in region $r$ and time $t$ (computed as $\sum_{o^{\prime} \neq o}^{64}$ Prop $_{o^{\prime}}$. Distance ${ }_{o o^{\prime}}$ ), the average distance to job openings in all other occupations in region $r$ and time $t$; distance to the 10 percent most distant occupations in region $r$ and time $t$ and the maximum distance in region $r$ and time $t$. 


\section{A.2 Data on Occupational Tasks (1979-1999)}

We use four cross-sections of the German Qualification and Career Survey conducted in 1979, 1985, 1991/92 and 1998/99 by the Federal Institute of Vocational Training (BIBB) and the Institute for Labor Market Research (IAB). The data with a sample size of 30,000 covers individuals between 16 and 65 , who are employed at the time of the survey. Just as in our main data set, we restrict our sample to men employed in West Germany and exclude the self-employed, civil servants and those working in agriculture. We also exclude those without German nationality since they were not included in each wave. We use the same 64 occupations based on a classification system by the Federal Employment Office, which is standardized over time. The aggregation at the 2-digit level decreases well-known measurement error problems of occupational classifications in survey data and allows us to match the data to our main data set.

For each respondent of the survey, we know whether the worker performs certain tasks in his job and whether this is his main activity on the job. Unlike the Dictionary of Occupational Titles (DOT) in the United States, we do not know how intensively a particular task is used beyond the distinction of main activity, task performed and not performed. Overall, we have information on 19 different tasks workers perform in their jobs. Following Autor et al. (2003), we also group the 19 tasks into three groups of tasks: analytical tasks, manual tasks and interactive tasks. The assignment of tasks is as follows: manual tasks (equip or operate machines, repair, reconstruct or renovate, cultivate, manufacture, cleaning, serve or accommodate, construct or install, pack or ship or transport, secure, nurse or treat others), analytical tasks (research or evaluate or measure, design or plan or sketch, correct texts or data, bookkeeping or calculate, program, execute laws or interpret rules) and interactive tasks (sell or buy or advertise, teach or train others, publish or present or entertain, employ or manage personnel or organize or coordinate). 
Table 1: Measuring Distance between Occupations

\begin{tabular}{lcc}
\hline \multicolumn{1}{c}{ Occupation 1 } & \multicolumn{1}{c}{ Distance Measure (19 Tasks) } \\
\cline { 2 - 3 } Mean & Occupation 2 & Distance \\
\hline \hline Standard Deviation & 0.0530 \\
& 0.0246 \\
Most Similar (all Education Groups) & \\
\hline Carpenter & Bricklayer, Mason & 0.0061 \\
Joiner, Cabinet Maker & Bricklayer, Mason & 0.0065 \\
Joiner, Cabinet Maker & Carpenter & 0.0078 \\
& & \\
Most Distant (all Education Groups) & 0.1611 \\
Banker & Assembler & 0.1633 \\
Banker & Unskilled Worker & 0.1635 \\
Banker & Metal Presser and Moulder
\end{tabular}

Most Common Occupational Moves (Low-Skilled)

Unskilled Worker $\quad$ Store or Warehouse Keeper $\quad 0.0226$

Truck Driver, Conductor Store or Warehouse Keeper $\quad 0.0226$

Assembler Store or Warehouse Keeper $\quad 0.0685$

Most Common Occupational Moves (Medium-Skilled)

Electricians, Electrical Installatioı Chemist, Physicist 0.0230

Sales Personnel Office Clerk 0.0259

Truck Driver, Conductor $\quad$ Store or Warehouse Keeper $\quad 0.0239$

Most Common Occupational Moves (High-Skilled)

\begin{tabular}{lll}
\hline Engineers & Chemist, Physicist & 0.0230 \\
Entrepreneurs & Office Clerk & 0.0257 \\
Accountant & Office Clerk & 0.0333
\end{tabular}

Notes: The table shows at the top summary statistics of the distance measure as well as the three most similar and distant occupations and their corresponding distance. The distance measure is based on the relative differences in using the 19 different tasks (see Table B1 for a list of tasks) and normalized to vary between 0 and 1 . The bottom part of the table shows the three most commonly observed moves in the data by education group and the corresponding distance measure. 
Table 2: Summary Statistics of West German Employee Panel

\begin{tabular}{|c|c|c|c|}
\hline & Low Skill & Medium Skill & High Skill \\
\hline Percentage in Sample & $16.27 \%$ & $68.30 \%$ & $15.43 \%$ \\
\hline Age (in Years) & $\begin{array}{l}25.82 \\
(6.26)\end{array}$ & $\begin{array}{l}27.47 \\
(5.24)\end{array}$ & $\begin{array}{l}31.85 \\
(5.60)\end{array}$ \\
\hline Not German Citizen & $\begin{array}{c}0.32 \\
(0.47)\end{array}$ & $\begin{array}{l}0.052 \\
(0.22)\end{array}$ & $\begin{array}{l}0.047 \\
(0.21)\end{array}$ \\
\hline Median Daily Wage & $\begin{array}{l}114.39 \\
(45.44)\end{array}$ & $\begin{array}{l}135.32 \\
(43.52)\end{array}$ & $\begin{array}{l}204.23 \\
(61.43)\end{array}$ \\
\hline Log Daily Wage & $\begin{array}{c}4.66 \\
(0.45)\end{array}$ & $\begin{array}{c}4.89 \\
(0.33)\end{array}$ & $\begin{array}{c}5.19 \\
(0.43)\end{array}$ \\
\hline Percentage censored & $\begin{array}{l}0.01 \\
(0.10)\end{array}$ & $\begin{array}{l}0.02 \\
(0.14)\end{array}$ & $\begin{array}{l}0.24 \\
(0.43)\end{array}$ \\
\hline Actual Experience (in Years) & $\begin{array}{l}5.76 \\
(5.40)\end{array}$ & $\begin{array}{c}5.59 \\
(4.76)\end{array}$ & $\begin{array}{c}5.25 \\
(4.81)\end{array}$ \\
\hline Occupational Tenure (in Years) & $\begin{array}{c}3.28 \\
(4.27)\end{array}$ & $\begin{array}{c}3.87 \\
(4.12)\end{array}$ & $\begin{array}{c}3.62 \\
(4.07)\end{array}$ \\
\hline Firm Tenure (in Years) & $\begin{array}{c}2.47 \\
(3.87)\end{array}$ & $\begin{array}{c}2.79 \\
(3.66)\end{array}$ & $\begin{array}{c}2.46 \\
(3.33)\end{array}$ \\
\hline Task Tenure (in Years) & $\begin{array}{l}4.58 \\
(4.65)\end{array}$ & $\begin{array}{l}4.81 \\
(4.28)\end{array}$ & $\begin{array}{l}4.66 \\
(4.38)\end{array}$ \\
\hline Occupational Mobility & $\begin{array}{c}0.186 \\
(0.389)\end{array}$ & $\begin{array}{c}0.114 \\
(0.317)\end{array}$ & $\begin{array}{c}0.109 \\
(0.311)\end{array}$ \\
\hline Similarity of Move & $\begin{array}{c}0.054 \\
(0.025)\end{array}$ & $\begin{array}{l}0.0525 \\
(0.025)\end{array}$ & $\begin{array}{l}0.0441 \\
(0.024)\end{array}$ \\
\hline Firm Mobility & $\begin{array}{c}0.236 \\
(0.425)\end{array}$ & $\begin{array}{c}0.18 \\
(0.384)\end{array}$ & $\begin{array}{c}0.18 \\
(0.384)\end{array}$ \\
\hline Most Common Occupations & $\begin{array}{l}\text { Warehouse Keeper (10\%) } \\
\text { Assembler (7\%) } \\
\text { Conductor (6\%) } \\
\text { Unskilled Worker (4\%) } \\
\text { Office Clerk (4\%) }\end{array}$ & $\begin{array}{l}\text { Electrical Installation (7\%) } \\
\text { Locksmith (8\%) } \\
\text { Mechanic, Machinist (6\%) } \\
\text { Office Clerk (7\%) } \\
\text { Conductor }(5 \%)\end{array}$ & $\begin{array}{l}\text { Engineer }(25 \%) \\
\text { Technician }(12 \%) \\
\text { Accountant }(9 \%) \\
\text { Office Clerk (8\%) } \\
\text { Researcher, Clergymen }(5 \%)\end{array}$ \\
\hline $\begin{array}{l}\text { Number of Observations } \\
\text { Number of Individuals in Sample }\end{array}$ & $\begin{array}{c}223,399 \\
18,604\end{array}$ & $\begin{array}{c}1,000,934 \\
78,101\end{array}$ & $\begin{array}{c}197,420 \\
17,648\end{array}$ \\
\hline
\end{tabular}

Notes: The table reports summary statistics for the administrative panel data on individual labor market histories and wages from 1975 to 2001. Low skilled workers are those without a vocational degree, medium skilled have either a high school or vocational degree and the high skilled have an advanced degree from a technical college or university. Experience, occupational, task and firm tenure are measured from actual spells and exclude periods of unemployment or out of the labor force. The wage is measured in German Marks at 1995 prices and is subject to right censoring.

Source: Employee Sample (IAB), 1975-2001 
Table 3: Observed Moves are More Similar than under Random Mobility

Random Mobility Observed Mobility

\begin{tabular}{lcc}
\hline & Random Mobility & Observed Mobility \\
Mean & 0.061 & 0.058 \\
10th Percentile & 0.027 & 0.021 \\
25th Percentile & 0.049 & 0.034 \\
50th Percentile & 0.066 & 0.058 \\
75th Percentile & 0.077 & 0.071 \\
90th Percentile & 0.083 & 0.078
\end{tabular}

Notes: The table repports selected moments of the distribution of observed occupational moves ("Observed Mobility") and compares it against what we would expect to observe under random mobility ("Random Mobility"). We calculate random mobility as follows: for each mover, we assume that the probability of going to any other occupation in the data is solely determined by the relative size of the target occupation. We then multiply this "random move" with its distance to get the distribution of the distance measure under random mobility. Since all moments of the observed distribution are below those under random mobility, individuals are much more likely to move to similar occupation. 
Table 4: Distance of Move Declines with Time in the Labor Market

\begin{tabular}{|c|c|c|c|c|c|c|c|c|c|}
\hline \multirow[b]{2}{*}{ Y: Distance (19 tasks) } & \multicolumn{3}{|c|}{ Low-Skilled } & \multicolumn{3}{|c|}{ Medium-Skilled } & \multicolumn{3}{|c|}{ High-Skilled } \\
\hline & $(1)$ & $(2)$ & $(3)$ & $(1)$ & $(2)$ & (3) & $(1)$ & $(2)$ & $(3)$ \\
\hline Experience ${ }^{\star} 100$ & $\begin{array}{c}-0.0765 \\
(0.0091)^{\star \star}\end{array}$ & $\begin{array}{c}-0.0700 \\
(0.0090)^{\star \star}\end{array}$ & $\begin{array}{c}-0.1021 \\
(0.0209)^{\star \star}\end{array}$ & $\begin{array}{c}-0.0447 \\
(0.0064)^{\star \star}\end{array}$ & $\begin{array}{c}-0.0421 \\
(0.0062)^{\star \star}\end{array}$ & $\begin{array}{c}-0.0983 \\
(0.0165)^{\star \star}\end{array}$ & $\begin{array}{c}-0.2308 \\
(0.0120)^{\star \star}\end{array}$ & $\begin{array}{c}-0.2246 \\
(0.0119)^{\star \star}\end{array}$ & $\begin{array}{c}-0.3371 \\
(0.0350)^{\star \star}\end{array}$ \\
\hline Experience Squared*100 & $\begin{array}{c}0.0025 \\
(0.0006)^{\star \star}\end{array}$ & $\begin{array}{c}0.0026 \\
(0.0006)^{\star \star}\end{array}$ & $\begin{array}{c}0.0030 \\
(0.0009)^{\star \star}\end{array}$ & $\begin{array}{c}0.0015 \\
(0.0004)^{\star \star}\end{array}$ & $\begin{array}{c}0.0015 \\
(0.0004)^{\star \star}\end{array}$ & $\begin{array}{c}0.0023 \\
(0.0007)^{\star \star}\end{array}$ & $\begin{array}{c}0.0102 \\
(0.0007)^{\star \star}\end{array}$ & $\begin{array}{c}0.0103 \\
(0.0007)^{\star \star}\end{array}$ & $\begin{array}{c}0.0111 \\
(0.0012)^{\star \star}\end{array}$ \\
\hline Occupation Tenure*100 & & $\begin{array}{c}-0.0574 \\
(0.0091)^{\star \star}\end{array}$ & $\begin{array}{c}-0.0272 \\
(0.0095)^{\star \star}\end{array}$ & & $\begin{array}{c}-0.0196 \\
(0.0051)^{\star \star}\end{array}$ & $\begin{array}{c}0.0129 \\
(0.0050)^{\star \star}\end{array}$ & & $\begin{array}{c}-0.0503 \\
(0.0093)^{\star \star}\end{array}$ & $\begin{array}{l}-0.0025 \\
(0.0116)\end{array}$ \\
\hline Constant & $\begin{array}{c}0.0573 \\
(0.0011)^{\star \star}\end{array}$ & $\begin{array}{c}0.0578 \\
(0.0011)^{\star \star}\end{array}$ & $\begin{array}{c}0.0551 \\
(0.0017)^{\star \star}\end{array}$ & $\begin{array}{c}0.0552 \\
(0.0012)^{\star \star}\end{array}$ & $\begin{array}{c}0.0553 \\
(0.0012)^{\star \star}\end{array}$ & $\begin{array}{c}0.0476 \\
(0.0021)^{\star \star}\end{array}$ & $\begin{array}{c}0.0592 \\
(0.0031)^{\star \star}\end{array}$ & $\begin{array}{c}0.0609 \\
(0.0030)^{\star \star}\end{array}$ & $\begin{array}{c}0.0378 \\
(0.0057)^{\star \star}\end{array}$ \\
\hline Year Dummies & Yes & Yes & Yes & Yes & Yes & Yes & Yes & Yes & Yes \\
\hline Occupation Dummies & Yes & Yes & Yes & Yes & Yes & Yes & Yes & Yes & Yes \\
\hline Individual Fixed Effects & No & No & Yes & No & No & Yes & No & No & Yes \\
\hline Observations & 44149 & 44149 & 44149 & 117206 & 117206 & 117206 & 20947 & 20947 & 20947 \\
\hline Mean Distance of Move & $\begin{array}{c}0.0542 \\
(0.0254)\end{array}$ & $\begin{array}{c}0.0542 \\
(0.0254)\end{array}$ & $\begin{array}{c}0.0542 \\
(0.0254)\end{array}$ & $\begin{array}{c}0.0525 \\
(0.0255)\end{array}$ & $\begin{array}{c}0.0525 \\
(0.0255)\end{array}$ & $\begin{array}{c}0.0525 \\
(0.0255)\end{array}$ & $\begin{array}{c}0.0441 \\
(0.0241)\end{array}$ & $\begin{array}{c}0.0441 \\
(0.0241)\end{array}$ & $\begin{array}{c}0.0441 \\
(0.0241)\end{array}$ \\
\hline
\end{tabular}

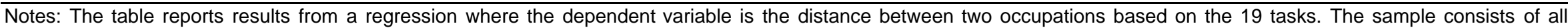

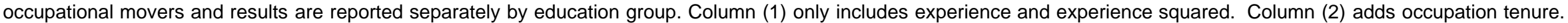

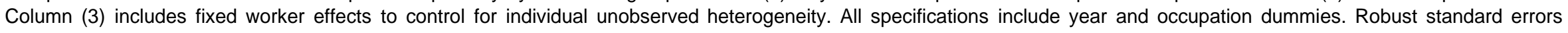
clustered at the individual level are reported in parentheses. Coefficients with * are statistically significant at the 5 percent level, those with ** at the 1 percent level. 
Table 5: Similar Moves and the Correlation of Wages Across Jobs

\begin{tabular}{|c|c|c|c|c|c|c|c|c|c|}
\hline \multirow[b]{2}{*}{ Y: Log Daily Wage after Move } & \multicolumn{3}{|c|}{ Low-Skilled } & \multicolumn{3}{|c|}{ Medium-Skilled } & \multicolumn{3}{|c|}{ High-Skilled } \\
\hline & $(1)$ & $(2)$ & (3) & (1) & (2) & (3) & $(1)$ & $(2)$ & (3) \\
\hline $\begin{array}{l}\text { Wage Last Period } \\
\text { Wage Last PeriodDistance }\end{array}$ & $\begin{array}{c}0.7832 \\
(0.0042)^{\star \star}\end{array}$ & $\begin{array}{c}0.2204 \\
(0.0066)^{\star \star}\end{array}$ & $\begin{array}{c}0.2763 \\
(0.0143)^{\star \star} \\
-1.0294 \\
(0.21228)^{\star \star}\end{array}$ & $\begin{array}{c}0.7868 \\
(0.00201)^{\star \star}\end{array}$ & $\begin{array}{c}0.3276 \\
(0.0043)^{\star \star}\end{array}$ & $\begin{array}{c}0.3990 \\
(0.0082)^{\star \star} \\
-1.3721 \\
(0.1317)^{\star \star}\end{array}$ & $\begin{array}{c}0.8902 \\
(0.0048)^{\star \star}\end{array}$ & $\begin{array}{c}0.2958 \\
(0.0100)^{\star *}\end{array}$ & $\begin{array}{c}0.3814 \\
(0.0163)^{\star \star} \\
-2.1085 \\
(0.3109)^{\star \star}\end{array}$ \\
\hline $\begin{array}{l}\text { Year Dummies } \\
\text { Occupation Dummies } \\
\text { Observations }\end{array}$ & $\begin{array}{c}\text { Yes } \\
\text { Yes } \\
158,808\end{array}$ & $\begin{array}{c}\text { Yes } \\
\text { Yes } \\
44,137\end{array}$ & $\begin{array}{c}\text { Yes } \\
\text { Yes } \\
44,137\end{array}$ & $\begin{array}{c}\text { Yes } \\
\text { Yes } \\
802,197\end{array}$ & $\begin{array}{c}\text { Yes } \\
\text { Yes } \\
117,204\end{array}$ & $\begin{array}{c}\text { Yes } \\
\text { Yes } \\
117,204\end{array}$ & $\begin{array}{c}\text { Yes } \\
\text { Yes } \\
158,416\end{array}$ & $\begin{array}{c}\text { Yes } \\
\text { Yes } \\
18,285\end{array}$ & $\begin{array}{c}\text { Yes } \\
\text { Yes } \\
18,285\end{array}$ \\
\hline
\end{tabular}

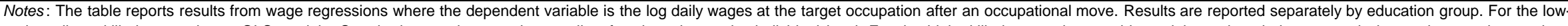
and medium-skilled, we estimate OLS models. Standard errors in parentheses allow for clustering at the individual level. For the high-skilled, we estimate tobit models, and exclude censored observations at the previous

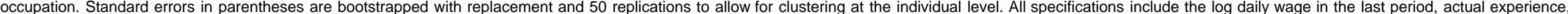

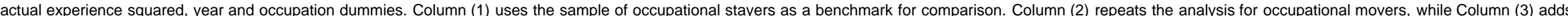

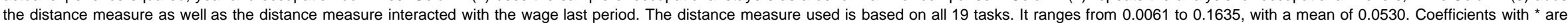
statistically significant at the 5 percent level, those with ${ }^{* \star}$ at the 1 percent level. 
Table 6: Past Occupational Tenure Matters for Wages

\begin{tabular}{|c|c|c|c|c|c|c|}
\hline \multirow[b]{2}{*}{ Y: Log Daily Wage after Move } & \multicolumn{2}{|c|}{ Low-Skilled } & \multicolumn{2}{|c|}{ Medium-Skilled } & \multicolumn{2}{|c|}{ High-Skilled } \\
\hline & $(1)$ & $(2)$ & $(1)$ & $(2)$ & $(1)$ & $(2)$ \\
\hline Past Occupational Tenure & $\begin{array}{c}0.0148 \\
(0.0009)^{\star *}\end{array}$ & $\begin{array}{c}0.0238 \\
(0.0015)^{\star \star}\end{array}$ & $\begin{array}{c}0.0129 \\
(0.0005)^{\star \star}\end{array}$ & $\begin{array}{c}0.0218 \\
(0.0008)^{\star \star}\end{array}$ & $\begin{array}{c}0.0150 \\
(0.0015)^{\star \star}\end{array}$ & $\begin{array}{c}0.0355 \\
(0.0020)^{\star \star}\end{array}$ \\
\hline Past Tenure *Distance & & $\begin{array}{c}-0.1709 \\
(0.0240)^{\star \star}\end{array}$ & & $\begin{array}{c}-0.1683 \\
(0.0109)^{\star \star}\end{array}$ & & $\begin{array}{c}-0.5235 \\
(0.0390)^{\star \star}\end{array}$ \\
\hline Year Dummies & Yes & Yes & Yes & Yes & Yes & Yes \\
\hline Occupational Dummies & Yes & Yes & Yes & Yes & Yes & Yes \\
\hline Observations & 44,149 & 44,149 & 117,206 & 117,206 & 20,947 & 20,947 \\
\hline
\end{tabular}

Notes: The table reports wage regressions where the dependent variable is the log wages in the target occupation after an occupational move. Estimates are reported for each education group separately. For the low- and medium-skilled, we report results from OLS regressions. Standard errors in parentheses allow for clustering at the individual level. For the high-skilled, we estimate tobit models. Standard errors in parentheses are bootstrapped with replacement and 50 replications to allow for clustering at the indidevel. Column (1) in each specification controls for past tenure in the source occupation, experience, experience squared, as well as year and occupation dummies. Column (2) additionally includes the distance measure interacted with past occupational tenure. The distance measure used is based on all 19 tasks. It ranges from 0.0061 to 0.1635 , with a mean of 0.0530 . Coefficients with * are statistically significant at the 5 percent level, those with ** at the 1 percent level. 


\begin{tabular}{|c|c|c|c|c|c|c|c|}
\hline & \multicolumn{2}{|c|}{ Whole Sample } & \multicolumn{2}{|c|}{ Starting New Job } & \multicolumn{3}{|c|}{ Displaced Workers } \\
\hline & (1) & (2) & (3) & (4) & (5) & (6) & (7) \\
\hline \multicolumn{8}{|l|}{ Panel A: Low-Skilled } \\
\hline Task Tenure & & $\begin{array}{c}0.008 \\
(0.0020)^{\star \star \star}\end{array}$ & & $\begin{array}{c}0.0159 \\
(0.0025)^{\star \star \star}\end{array}$ & & $\begin{array}{c}0.0324 \\
(0.004)^{\star \star \star}\end{array}$ & $\begin{array}{c}0.0205 \\
(0.0067)^{\star \star \star}\end{array}$ \\
\hline Occupational Tenure & $\begin{array}{c}0.0096 \\
(0.0007)^{\star \star \star}\end{array}$ & $\begin{array}{c}0.0062 \\
(0.0010)^{\star \star \star}\end{array}$ & $\begin{array}{c}0.0213 \\
(0.0009)^{\star \star \star}\end{array}$ & $\begin{array}{c}0.0148 \\
(0.0013)^{\star \star \star}\end{array}$ & $\begin{array}{c}0.0161 \\
(0.0019)^{\star \star \star}\end{array}$ & & $\begin{array}{c}0.0077 \\
(0.0032)^{\star *}\end{array}$ \\
\hline Experience & $\begin{array}{c}0.0702 \\
(0.0009)^{\star \star \star}\end{array}$ & $\begin{array}{c}0.0659 \\
(0.0015)^{\star \star \star}\end{array}$ & $\begin{array}{c}0.0452 \\
(0.0014)^{\star \star \star}\end{array}$ & $\begin{array}{c}0.0369 \\
(0.0019)^{\star \star \star}\end{array}$ & $\begin{array}{c}0.0413 \\
(0.0035)^{\star \star \star}\end{array}$ & $\begin{array}{c}0.0249 \\
(0.0043)^{\star \star \star}\end{array}$ & $\begin{array}{c}0.0304 \\
(0.0051)^{\star \star \star}\end{array}$ \\
\hline Experience Squared & $\begin{array}{c}-0.0025 \\
(0.0000)^{\star \star \star}\end{array}$ & $\begin{array}{c}-0.0025 \\
(0.0000)^{\star \star \star}\end{array}$ & $\begin{array}{c}-0.0014 \\
(0.0001)^{\star \star \star}\end{array}$ & $\begin{array}{c}-0.0015 \\
(0.0001)^{\star \star \star}\end{array}$ & $\begin{array}{c}-0.0011 \\
(0.0002)^{\star \star \star}\end{array}$ & $\begin{array}{c}-0.0012 \\
(0.0002)^{\star \star \star}\end{array}$ & $\begin{array}{c}-0.0012 \\
(0.0002)^{\star \star \star}\end{array}$ \\
\hline Firm Tenure & $\begin{array}{c}0.0077 \\
(0.0006)^{\star \star \star}\end{array}$ & $\begin{array}{c}0.0078 \\
(0.0006)^{\star \star \star}\end{array}$ & & & & & \\
\hline Observations & 221114 & 221114 & 57217 & 57217 & 5923 & 5923 & 5923 \\
\hline R Squared & 0.42 & 0.42 & 0.3 & 0.31 & 0.34 & 0.34 & 0.35 \\
\hline \multicolumn{8}{|c|}{ Panel B: Medium-Skilled } \\
\hline Task Tenure & & $\begin{array}{c}0.0085 \\
(0.0010)^{\star \star \star}\end{array}$ & & $\begin{array}{c}0.0195 \\
(0.0014)^{\star \star \star}\end{array}$ & & $\begin{array}{c}0.0315 \\
(0.0021)^{\star \star \star}\end{array}$ & $\begin{array}{c}0.0166 \\
(0.0036)^{\star \star \star}\end{array}$ \\
\hline Occupational Tenure & $\begin{array}{c}0.0072 \\
(0.0003)^{\star \star \star}\end{array}$ & $\begin{array}{c}0.0037 \\
(0.0005)^{\star \star \star}\end{array}$ & $\begin{array}{c}0.0168 \\
(0.0004)^{\star \star \star}\end{array}$ & $\begin{array}{c}0.0092 \\
(0.0006)^{\star \star \star}\end{array}$ & $\begin{array}{c}0.0152 \\
(0.0009)^{\star \star \star}\end{array}$ & & $\begin{array}{c}0.0088 \\
(0.0016)^{\star \star \star}\end{array}$ \\
\hline Experience & $\begin{array}{c}0.0424 \\
(0.0004)^{\star \star \star}\end{array}$ & $\begin{array}{c}0.0375 \\
(0.0007)^{\star \star \star}\end{array}$ & $\begin{array}{c}0.0365 \\
(0.0007)^{\star \star \star}\end{array}$ & $\begin{array}{c}0.0256 \\
(0.0011)^{\star \star \star}\end{array}$ & $\begin{array}{c}0.0341 \\
(0.0018)^{\star \star \star}\end{array}$ & $\begin{array}{c}0.0175 \\
(0.0024)^{\star \star \star}\end{array}$ & $\begin{array}{c}0.0245 \\
(0.0028)^{\star \star \star}\end{array}$ \\
\hline Experience Squared & $\begin{array}{c}-0.0015 \\
(0.0000)^{\star \star \star}\end{array}$ & $\begin{array}{c}-0.0015 \\
(0.0000)^{\star \star \star}\end{array}$ & $\begin{array}{c}-0.0012 \\
(0.0000)^{\star \star \star}\end{array}$ & $\begin{array}{c}-0.0012 \\
(0.0000)^{\star \star \star}\end{array}$ & $\begin{array}{c}-0.001 \\
(0.0001)^{\star \star \star}\end{array}$ & $\begin{array}{c}-0.0011 \\
(0.0001)^{\star \star \star}\end{array}$ & $\begin{array}{c}-0.0011 \\
(0.0001)^{\star \star \star}\end{array}$ \\
\hline Firm Tenure & $\begin{array}{c}0.0073 \\
(0.0002)^{\star \star \star}\end{array}$ & $\begin{array}{c}0.0074 \\
(0.0002)^{\star \star \star}\end{array}$ & & & & & \\
\hline Observations & 997215 & 997215 & 189145 & 189145 & 21344 & 21344 & 21344 \\
\hline R Squared & 0.38 & 0.38 & 0.29 & 0.29 & 0.3 & 0.3 & 0.3 \\
\hline \multicolumn{8}{|l|}{ Panel C: High-Skilled } \\
\hline Task Tenure & & $\begin{array}{c}0.0628 \\
(0.0016)^{\star \star}\end{array}$ & & $\begin{array}{c}0.0644 \\
(0.0028)^{\star \star}\end{array}$ & & $\begin{array}{c}0.0442 \\
(0.0058)^{\star \star \star}\end{array}$ & $\begin{array}{c}0.0522 \\
(0.0090)^{\star \star}\end{array}$ \\
\hline Occupational Tenure & $\begin{array}{c}0.0058 \\
(0.0004)^{\star \star}\end{array}$ & $\begin{array}{c}-0.015 \\
(0.0007)^{\star \star}\end{array}$ & $\begin{array}{c}0.0121 \\
(0.0008)^{\star \star}\end{array}$ & $\begin{array}{c}-0.0078 \\
(0.0012)^{\star \star}\end{array}$ & $\begin{array}{c}0.0119 \\
(0.0026)^{\star \star}\end{array}$ & & $\begin{array}{l}-0.0051 \\
(0.0039)\end{array}$ \\
\hline Experience & $\begin{array}{c}0.0829 \\
(0.0006)^{\star \star}\end{array}$ & $\begin{array}{c}0.0423 \\
(0.0012)^{\star \star}\end{array}$ & $\begin{array}{c}0.0668 \\
(0.0013)^{\star \star}\end{array}$ & $\begin{array}{c}0.0251 \\
(0.0023)^{\star \star}\end{array}$ & $\begin{array}{c}0.0551 \\
(0.0049)^{\star \star}\end{array}$ & $\begin{array}{c}0.0243 \\
(0.0066)^{\star \star \star}\end{array}$ & $\begin{array}{c}0.0221 \\
(0.0075)^{\star \star}\end{array}$ \\
\hline Experience Squared & $\begin{array}{c}-0.0031 \\
(0.0000)^{\star \star}\end{array}$ & $\begin{array}{c}-0.0031 \\
(0.0000)^{\star \star}\end{array}$ & $\begin{array}{c}-0.0026 \\
(0.0001)^{\star \star}\end{array}$ & $\begin{array}{c}-0.0027 \\
(0.0001)^{\star \star}\end{array}$ & $\begin{array}{c}-0.002 \\
(0.0003)^{\star \star}\end{array}$ & $\begin{array}{c}-0.0020 \\
(0.0003)^{\star \star \star}\end{array}$ & $\begin{array}{c}-0.0021 \\
(0.0003)^{\star \star}\end{array}$ \\
\hline Firm Tenure & $\begin{array}{c}0.0091 \\
(0.0004)^{\star \star}\end{array}$ & $\begin{array}{c}0.0091 \\
(0.0004)^{\star \star}\end{array}$ & & & & & \\
\hline Observations & 196900 & 196900 & 35072 & 35072 & 2644 & 2644 & 2644 \\
\hline Log-Likelihood & -93460.3 & -92772.3 & -14300.1 & -14050.7 & -933.6 & -916.3 & -915.4 \\
\hline
\end{tabular}

Note: The table reports results from a regression of the log daily wage on general human capital (experience, experience squared), firm tenure, occupation and task tenure. All specifications include year, region and occupation dummies. Panel $\mathrm{C}$ estimates tobit models to account for censoring. Specifications in columns (2), (4) and (7) add our measure of task tenure to the specification in columns (1), (3) and (5). Columns (6) only includes our measure of task tenure, experience and experience squared. Columns (1)-(2) are estimated for the whole sample, columns (3)-(4) on those starting a new firm and columns (5)-(7) on our sample of displaced workers. Standard errors allow for clustering at the individual level. For Panel $C$ standard errors are bootstrapped with 50 replications to account for clustering at the individual level. Coefficients with ${ }^{* * *},{ }^{* *},{ }^{*}$ are significant at the 1,5 and 10 percent level respectively. 
Table 8: Importance of Task Human Capital to Individual Wage Growth

\begin{tabular}{|c|c|c|c|c|c|c|c|}
\hline & \multicolumn{2}{|c|}{$\begin{array}{c}\text { Starting New Job } \\
\text { FD/FE }\end{array}$} & \multicolumn{2}{|c|}{$\begin{array}{c}\text { Displaced Workers } \\
\text { First Differences }\end{array}$} & \multicolumn{3}{|c|}{$\begin{array}{c}\text { Displaced Workers } \\
\text { IV }\end{array}$} \\
\hline & $(1)$ & $(2)$ & (3) & $(4)$ & (5) & (6) & $(7)$ \\
\hline \multicolumn{8}{|l|}{ Panel A: Low-Skilled } \\
\hline \multirow[t]{2}{*}{ Task Tenure } & & 0.0084 & & 0.0008 & & 0.141 & 0.1235 \\
\hline & & $(0.0029)^{\star \star \star}$ & & $(0.0082)$ & & $(0.0677)^{\star \star}$ & $(0.1515)$ \\
\hline \multirow[t]{2}{*}{ Occupational Tenure } & 0.0085 & 0.0052 & 0.0037 & 0.0034 & 0.0696 & & -0.0107 \\
\hline & $(0.0009)^{\star \star \star}$ & $(0.0014)^{\star \star \star}$ & $(0.0023)$ & $(0.0038)$ & $(0.0420)^{*}$ & & 0.0700 \\
\hline \multirow[t]{2}{*}{ Experience } & 0.0779 & 0.0744 & 0.0676 & 0.0673 & 0.035 & -0.0320 & -0.0141 \\
\hline & $(0.0086)^{\star \star \star}$ & $(0.0087)^{\star \star \star}$ & $(0.0263)^{\star \star}$ & $(0.0265)^{\star \star}$ & $(0.0206)^{\star}$ & $(0.0482)$ & $(0.0779)$ \\
\hline \multirow[t]{2}{*}{ Experience Squared } & -0.0063 & -0.0064 & -0.0038 & -0.0038 & -0.0025 & -0.0029 & -0.003 \\
\hline & $(0.0004)^{\star \star \star}$ & $(0.0004)^{\star \star \star}$ & $(0.0013)^{\star \star \star}$ & $(0.0013)^{\star \star \star}$ & $(0.0004)^{\star \star \star}$ & $(0.0004)^{\star \star \star}$ & $(0.0007)^{\star \star \star}$ \\
\hline Firm Tenure & & & $\begin{array}{l}-0.0028 \\
(0.0020)\end{array}$ & $\begin{array}{l}-0.0028 \\
(0.0020)\end{array}$ & & & \\
\hline Observations & 56813 & 56813 & 5891 & 5891 & 5789 & 5789 & 5789 \\
\hline R Squared & 0.06 & 0.06 & 0.09 & 0.09 & & & \\
\hline \multicolumn{8}{|c|}{ Panel B: Medium-Skilled } \\
\hline Task Tenure & & $\begin{array}{c}0.0109 \\
(0.0015)^{\star \star \star}\end{array}$ & & $\begin{array}{c}0.0048 \\
(0.0045)\end{array}$ & & $\begin{array}{c}0.0639 \\
(0.0980)\end{array}$ & $\begin{array}{c}0.0544 \\
(0.8831)\end{array}$ \\
\hline Occupational Tenure & $\begin{array}{c}0.0081 \\
(0.0004)^{\star \star \star}\end{array}$ & $\begin{array}{c}0.0039 \\
(0.0007)^{\star \star \star}\end{array}$ & $\begin{array}{c}0.0051 \\
(0.0011)^{\star \star \star}\end{array}$ & $\begin{array}{c}0.0033 \\
(0.0019)^{\star}\end{array}$ & $\begin{array}{l}-0.0425 \\
(0.0368)\end{array}$ & & $\begin{array}{l}-0.0231 \\
(0.4651)\end{array}$ \\
\hline Experience & $\begin{array}{c}-0.0104 \\
(0.0032)^{\star \star \star}\end{array}$ & $\begin{array}{c}-0.0158 \\
(0.0033)^{\star \star \star}\end{array}$ & $\begin{array}{c}0.006 \\
(0.0098)\end{array}$ & $\begin{array}{c}0.0034 \\
(0.0102)\end{array}$ & $\begin{array}{c}0.0706 \\
(0.0224)^{\star \star \star}\end{array}$ & $\begin{array}{c}0.0096 \\
(0.0783)\end{array}$ & $\begin{array}{c}0.0154 \\
(0.4255)\end{array}$ \\
\hline Experience Squared & $\begin{array}{c}-0.0023 \\
(0.0002)^{\star \star \star}\end{array}$ & $\begin{array}{c}-0.0024 \\
(0.0002)^{\star \star \star}\end{array}$ & $\begin{array}{c}-0.0029 \\
(0.0005)^{\star \star \star}\end{array}$ & $\begin{array}{c}-0.0029 \\
(0.0005)^{\star \star \star}\end{array}$ & $\begin{array}{c}-0.0018 \\
(0.0003)^{\star \star \star}\end{array}$ & $\begin{array}{c}-0.0016 \\
(0.0002)^{\star \star \star}\end{array}$ & $\begin{array}{l}-0.0018 \\
(0.0025)\end{array}$ \\
\hline Firm Tenure & $\begin{array}{l}-0.0005 \\
(0.0003)\end{array}$ & $\begin{array}{l}-0.0006 \\
(0.0003)^{\star}\end{array}$ & $\begin{array}{c}0.0003 \\
(0.0009)\end{array}$ & $\begin{array}{c}0.0003 \\
(0.0009)\end{array}$ & & & \\
\hline Observations & 188381 & 188381 & 21286 & 21286 & 21012 & 21012 & 21012 \\
\hline R Squared & 0.04 & 0.04 & 0.03 & 0.03 & & & \\
\hline \multicolumn{8}{|l|}{ Panel C: High-Skilled } \\
\hline Task Tenure & & $\begin{array}{c}0.0529 \\
(0.0029)^{\star \star \star}\end{array}$ & & & & $\begin{array}{c}0.1242 \\
(0.0729)^{\star}\end{array}$ & $\begin{array}{c}0.0762 \\
(0.1283)\end{array}$ \\
\hline Occupational Tenure & $\begin{array}{c}0.0096 \\
(0.0008)^{\star \star \star}\end{array}$ & $\begin{array}{c}-0.0059 \\
(0.0012)^{\star \star \star}\end{array}$ & & & $\begin{array}{c}0.0919 \\
(0.0456)^{\star \star}\end{array}$ & & $\begin{array}{c}0.0185 \\
(0.0733)\end{array}$ \\
\hline Experience & $\begin{array}{c}0.0683 \\
(0.0013)^{\star \star \star}\end{array}$ & $\begin{array}{c}0.0333 \\
(0.0023)^{\star \star \star}\end{array}$ & & & $\begin{array}{c}0.0068 \\
(0.0268)\end{array}$ & $\begin{array}{l}-0.0384 \\
(0.0576)\end{array}$ & $\begin{array}{l}-0.0178 \\
(0.0657)\end{array}$ \\
\hline Experience Squared & $\begin{array}{c}-0.0026 \\
(0.00007)^{\star \star \star}\end{array}$ & $\begin{array}{c}-0.0027 \\
(0.00007)^{\star \star \star}\end{array}$ & & & $\begin{array}{c}-0.0015 \\
(0.0006)^{\star \star}\end{array}$ & $\begin{array}{c}-0.0023 \\
(0.0004)^{\star \star \star}\end{array}$ & $\begin{array}{c}-0.0020 \\
(0.0007)^{\star \star}\end{array}$ \\
\hline \multicolumn{8}{|l|}{ Firm Tenure } \\
\hline Observations & 35072 & 35072 & & & 2609 & 2609 & 2609 \\
\hline Log-Likelihood & -12416.7 & -12249.6 & & & -336.9 & -337 & -336.1 \\
\hline
\end{tabular}


Figure 1a: Quarterly Occupation Quit Rate by Time in the Labor Market

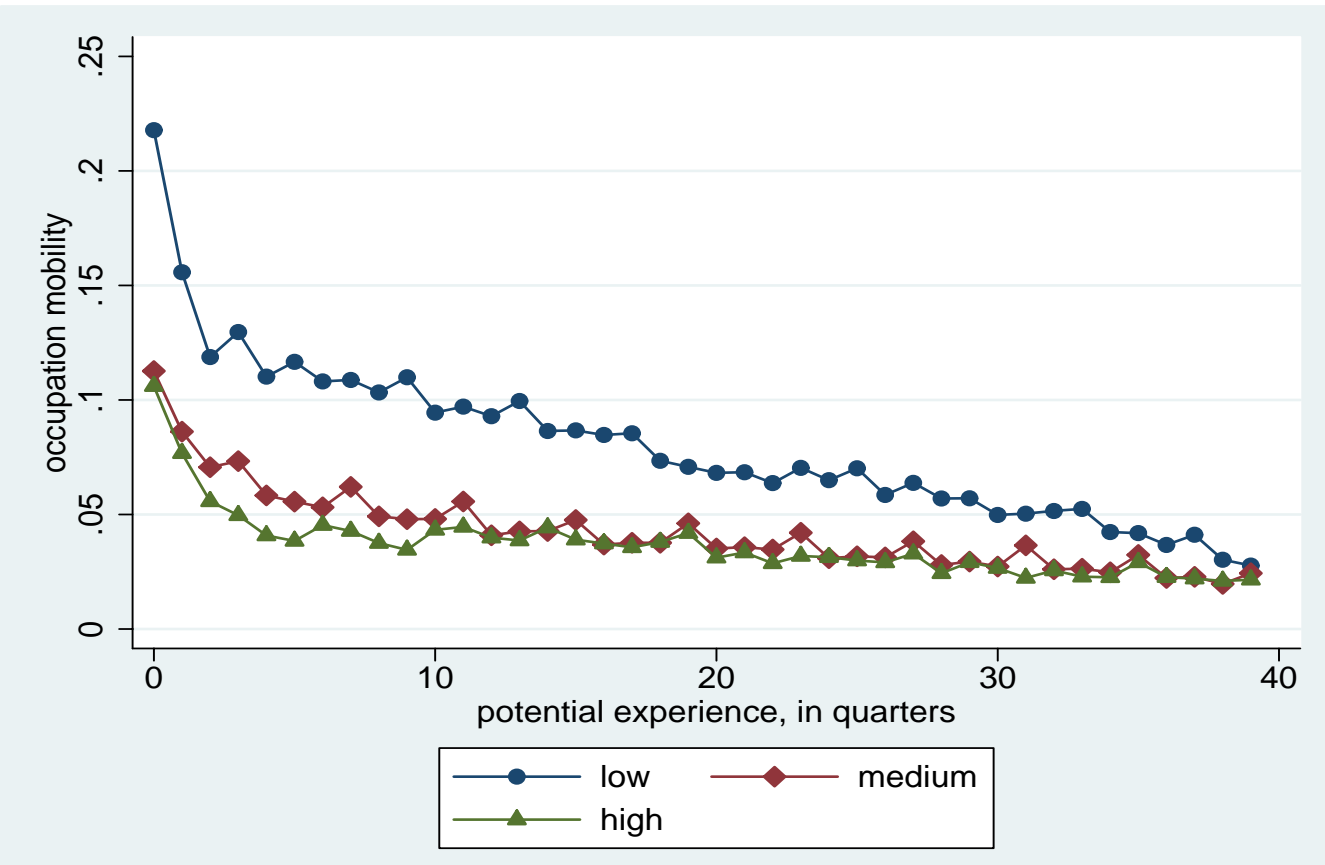

Figure 1b: Quarterly Firm Quit Rate by Time in the Labor Market

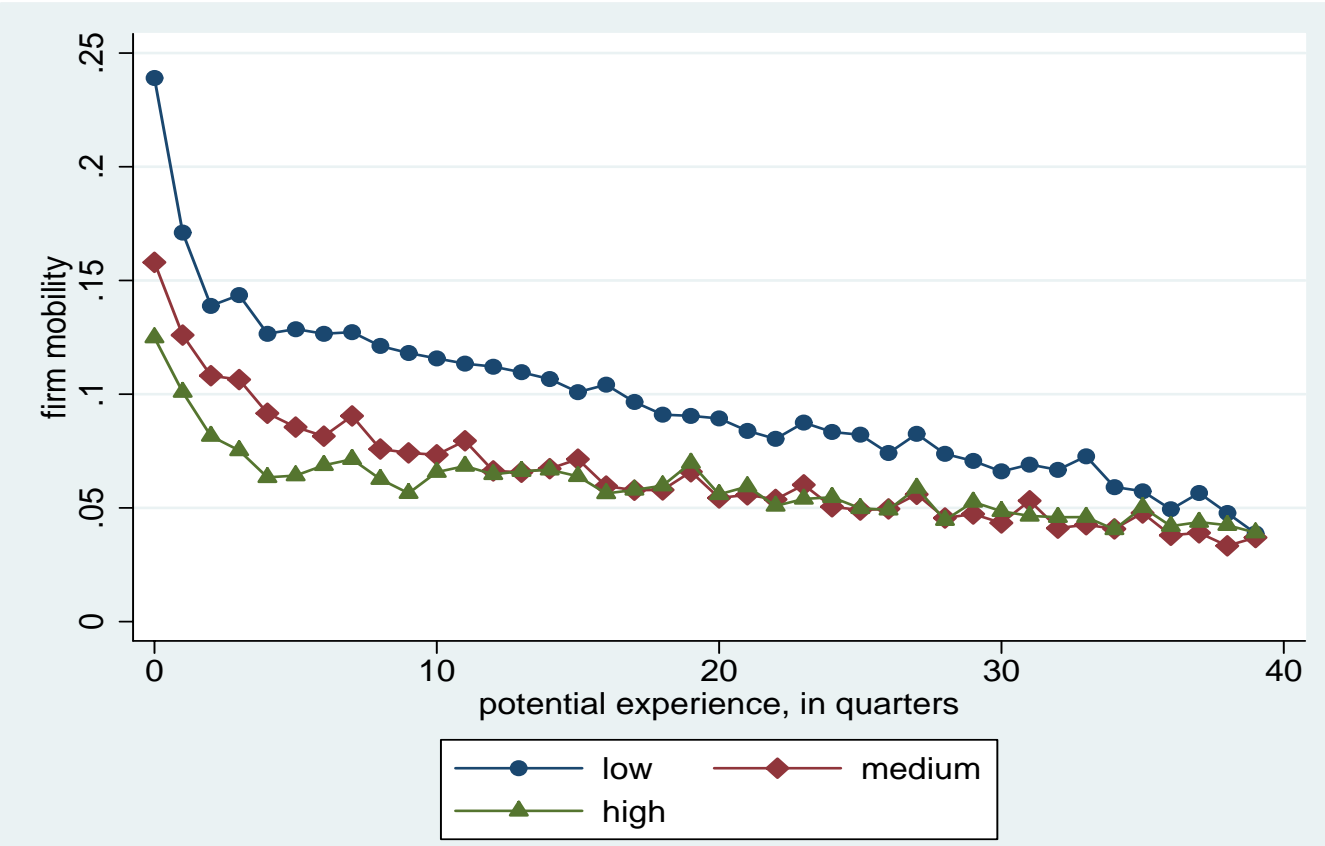

Notes: The upper panel shows the quarterly occupation quit rate by education and time in the labor market (potential experience). For comparison, the lower panel plots the quarterly firm quit rates by education and potential experience. Quit rates are only defined for workers who are employed at the beginning of the quarter. 
Figure 2: Observed Mobility is More Similar Than Random Mobility

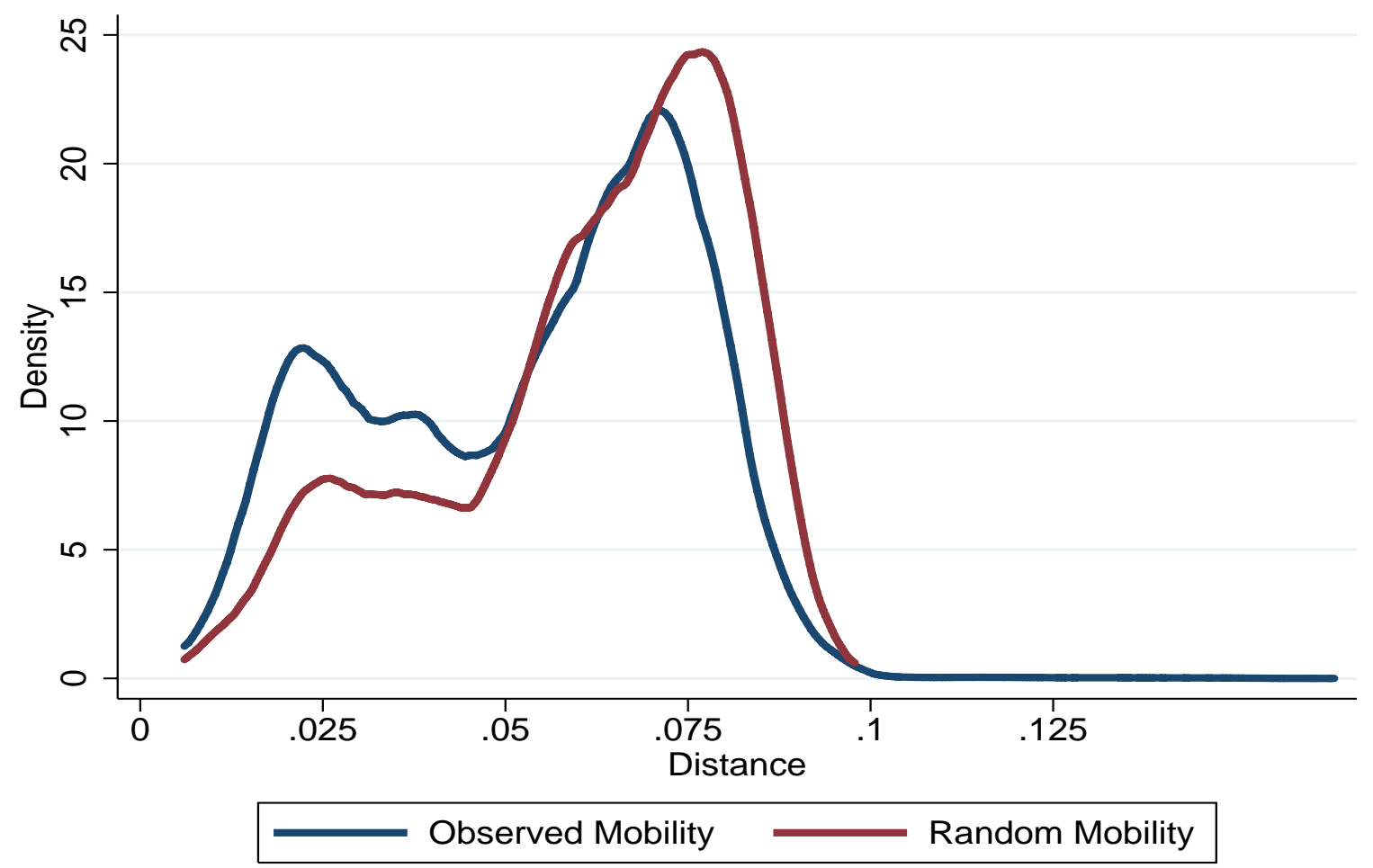

Notes: The figure plots the density of the distance measure under observed and random mobility. We calculate random mobility as follows: for each mover, we assume that the probability of going to any other occupation in the data is solely determined by the relative size of the target occupation. We then multiply this "random move" with its distance to get the distribution of the distance measure under random mobility. Distance measure: 19 tasks. 
Figure 3: Distance of Occupational Moves Declines over Career

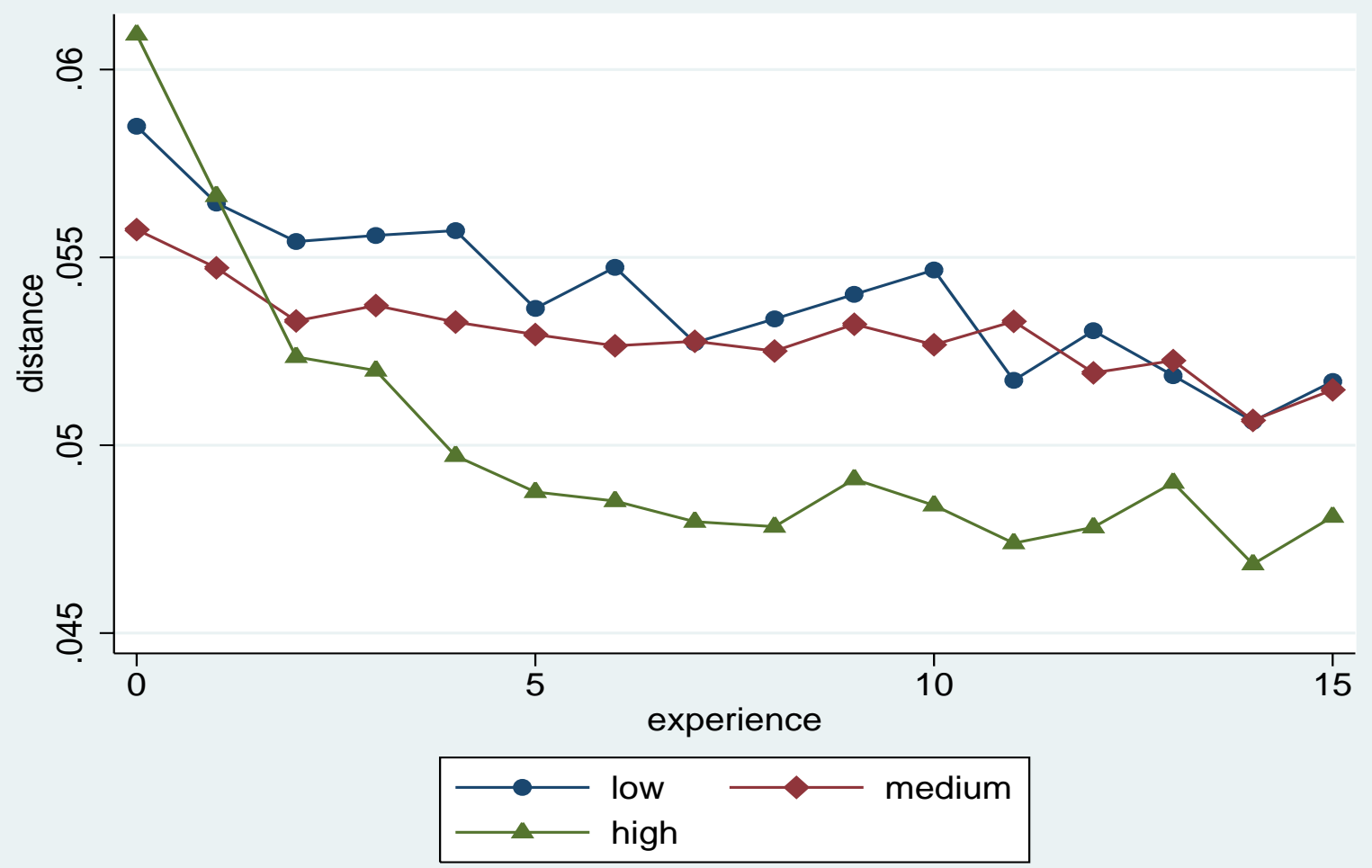

Notes: The figure plots the average distance of the occupational move by actual experience. Regressions control for 15 experience dummies, occupation dummies, and time dummies. The decline in the average distance by experience is significant at a $1 \%$ level for all education groups. Distance measure: 19 tasks. 
Figure 4a: Correlation of Wages by Distance of Move

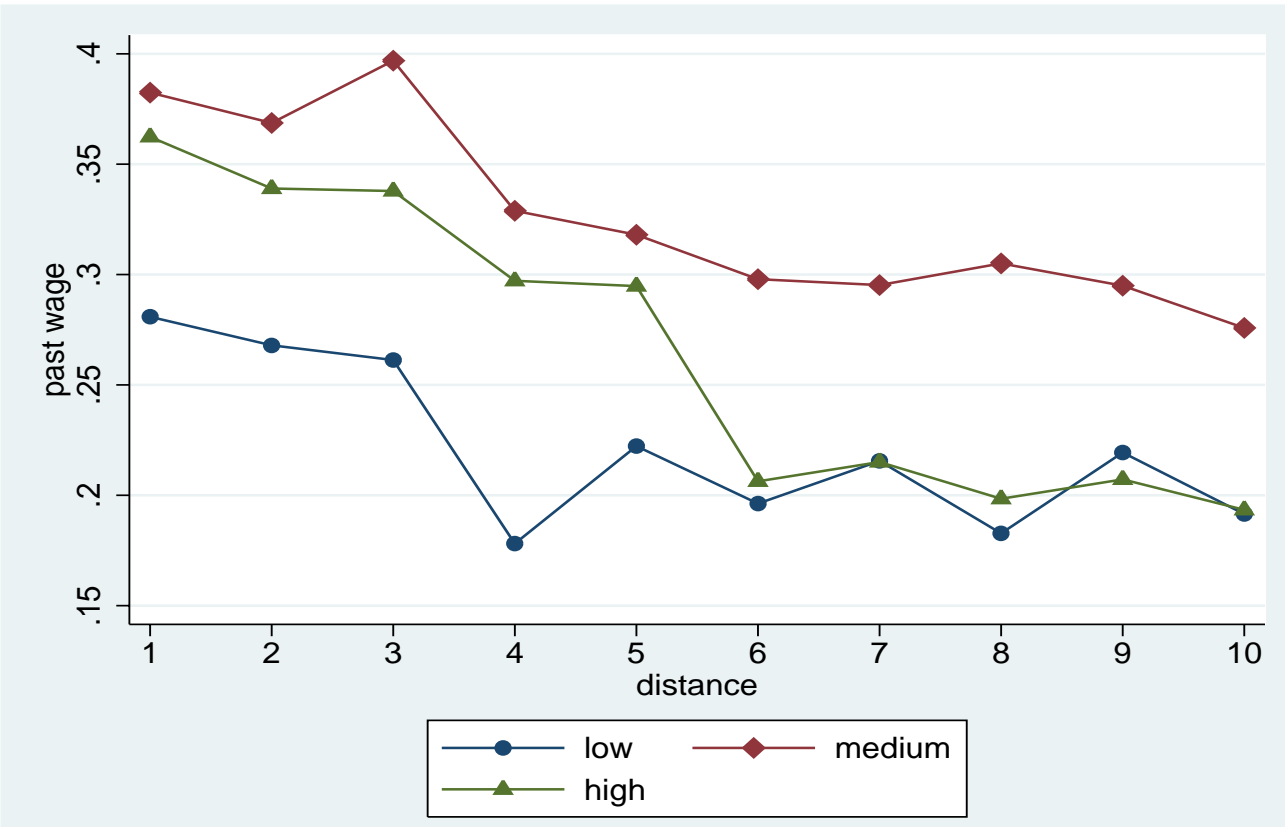

Figure 4b: Impact of Past Occupational Tenure by Distance of Move

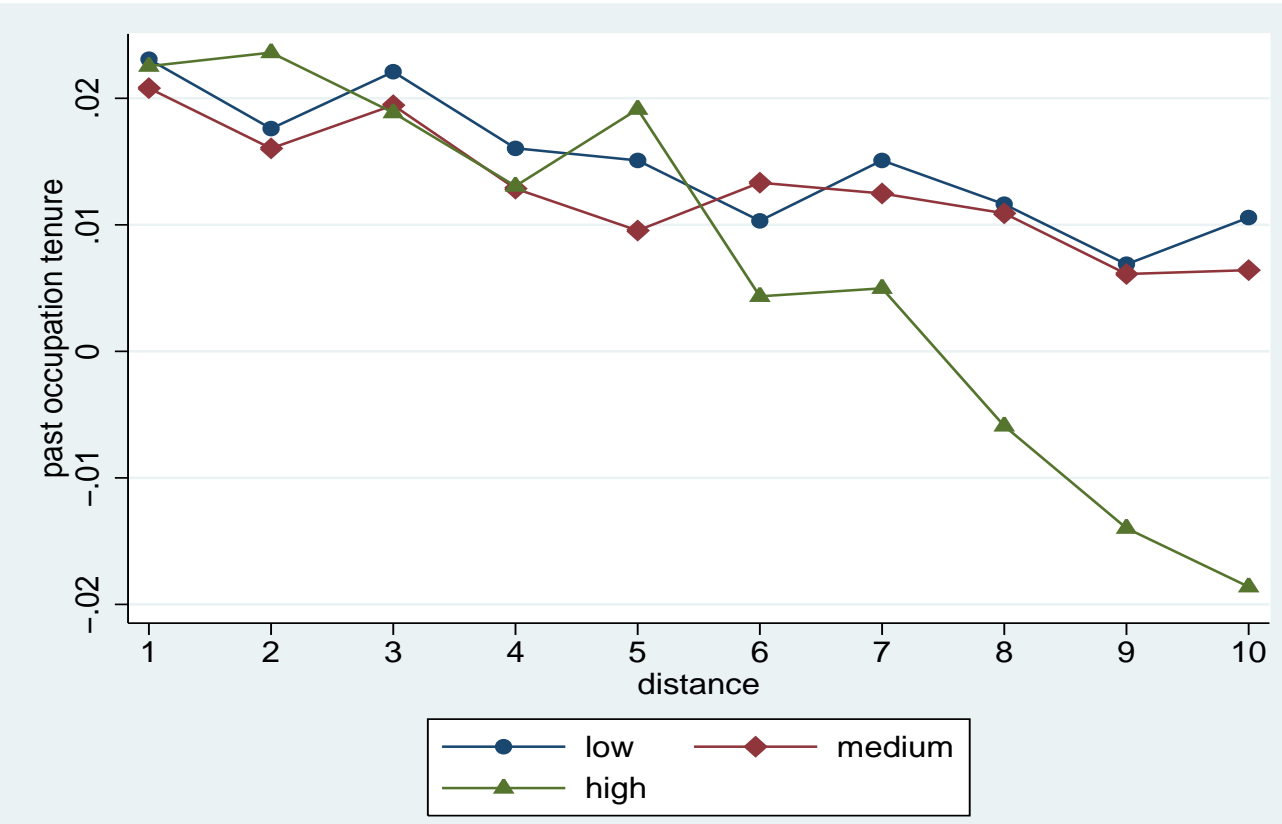

Notes: The upper panel plots the impact of the past wage on the current wage by the distance of the occupational move. Regressions control for occupation and time dummies, past wages, ten distance dummies as well as the past wage interacted with the 10 distance dummies. The lower panel plots the impact of past occupation tenure on current wages by the distance of the occupational move. Regressions control for occupation and time dummies, past occupation tenure and past occupation tenure interacted with ten distance dummies. 
Table B1: Summary Statistics of Task Data

\begin{tabular}{|c|c|c|c|c|}
\hline & Mean & Std.Dev & Example: Teacher & Example: Baker \\
\hline Analytical Tasks & 55.02 & 49.75 & $63.73 \%$ & $32.42 \%$ \\
\hline Research, evaluate or measure & 25.11 & 43.37 & $34.02 \%$ & $13.56 \%$ \\
\hline Design, plan or sketch & 10.21 & 30.28 & $17.62 \%$ & $3.60 \%$ \\
\hline Correct texts or data & 23.85 & 42.62 & $39.64 \%$ & $6.36 \%$ \\
\hline Calculate or bookkeeping & 26.02 & 43.87 & $11.34 \%$ & $22.46 \%$ \\
\hline Program & 8.35 & 27.66 & $8.43 \%$ & $0.42 \%$ \\
\hline Execute laws or interpret rules & 7.85 & 26.89 & $17.24 \%$ & $0.85 \%$ \\
\hline Analytical is Main Task & 31.56 & 46.48 & $15.93 \%$ & $13.14 \%$ \\
\hline Manual Tasks & 72.42 & 44.69 & $25.59 \%$ & $96.40 \%$ \\
\hline Equip or operate machines & 19.98 & 39.99 & $7.03 \%$ & $27.12 \%$ \\
\hline Repair, renovate or reconstruct & 31.38 & 46.40 & $8.15 \%$ & $10.38 \%$ \\
\hline Cultivate & 1.77 & 13.19 & $2.25 \%$ & $1.91 \%$ \\
\hline Manufacture, install or construct & 11.97 & 32.46 & $1.97 \%$ & $87.92 \%$ \\
\hline Cleaning & 3.50 & 18.38 & $1.78 \%$ & $6.14 \%$ \\
\hline Serve or accommodate & 1.21 & 10.92 & $0.28 \%$ & $3.60 \%$ \\
\hline Pack, ship or transport & 18.76 & 39.04 & $2.72 \%$ & $15.25 \%$ \\
\hline Secure & 15.72 & 36.40 & $7.22 \%$ & $18.01 \%$ \\
\hline Nurse or treat others & 9.76 & 29.67 & $11.53 \%$ & $7.84 \%$ \\
\hline Manual is Main Task & 57.46 & 49.44 & $10.50 \%$ & $88.77 \%$ \\
\hline Interactive Tasks & 48.48 & 49.98 & $95.31 \%$ & $44.07 \%$ \\
\hline Sell, buy or advertise & 29.21 & 45.48 & $12.00 \%$ & $16.53 \%$ \\
\hline Teach or train others & 17.15 & 37.69 & $91.38 \%$ & $34.32 \%$ \\
\hline Publish, present or entertain others & 9.58 & 29.43 & $26.24 \%$ & $3.81 \%$ \\
\hline Employ, manage personnel, organize, coord & 37.09 & 48.31 & $39.36 \%$ & $29.87 \%$ \\
\hline Interactive is Main Task & 27.55 & 44.68 & $85.94 \%$ & $14.83 \%$ \\
\hline Observations & 52,718 & & 1,067 & 472 \\
\hline
\end{tabular}

Source : Qualification and Career Survey: 1979, 1985, 1991/2, 1997/8 
Table B2: List of Occupations and Task Usage

Title of Occupation $\quad$ Employed (\%) Manual Tasks

Analytic Tasks $\quad$ Interactive Tasks

Miners, Stone-Breaker, Mineral Processing

Concrete and Cement Finishers, Stone Processing

Potter, Ceramicist, Gaffer

Chemical Processing

Plastics and Polymer Processing

Paper and Pulp Processing

Printer, Typesetter, Typographer

Wood, Lumber and Timber Processing

Metal and Iron Manufacturer

Moulding, Shaping

Metal Presser and Moulder

Metal Polisher, Sanders, Buffers, Lathe Operators

Welder, Brazing, Soldering

Blacksmith, Farrier, Forger, Plumber and Pipe Fitters

Locksmith

Mechanic, Machinist, Repairmen

Tool and Dye Maker, Instrument Mechanic

Metal Craftsmen

Electricians, Electrical Installation

Assembler

Weaver, Spinner, Knitters, Wool Trade

Tailor, Textile Worker

Shoemaker

Baker

Butcher

Cook

Beverage Production, Milk Production, Grease Processing

Bricklayer, Mason

Carpenter

Road Builder

Unskilled Construction Worker

Plasterer

Interior Decorator, Interior Designer

Joiner, Cabinet Maker

Painters

Product Tester

Unskilled Worker

Crane Driver, Crane Operator, Skinner, Machine Operator

Engineers

Chemist, Physicist,

Technical Service Persone

Sales Personnel

Banker

Traders, Trading Personnel

Truck Driver, Conductor

Sailor, Seaman, Navigator, Mariner

Mail Carrier and Handlers, Postal Clerks

Storekeeper, Warehouse Keeper

Entrepreneurs

Politicians, Member of Parliament

Accountant, Book Keeper

Office Clerk

Guards, Watchmen, Police, Security Personnel

Publicist, Journalist, Authors

Musicians

Physicians

Nurses, Dietitians, Physical Therapists

Social Worker

Teacher (except university)

Scientist, Clergymen

Personal Hygiene Technician

Waiter, Barkeeper, Innkeepe

Janitor, Home Economics, Housekeeper

Cleaning Service Workers

\subsection{1}

0.36

0.36

1.65

1.14

0.68

0.83

0.46

0.41

0.38

0.54

2.26

0.51

3.24

6.23

4.26

1.29

0.34

5.49

2.75

0.13

0.19

0.22

1.00

1.02

1.21

0.47

2.52

1.61

0.79

1.24

1.09

0.31

285

2.20

1.70

1.69

0.91

3.64

4.46

1.05

4.90

2.97

0.77

3.99

0.12

0.47

4.57

1.64

0.26

2.23

6.21

1.08

0.17

0.41

0.51

0.76

0.58

0.91

0.84

0.12

0.64

0.03

1.04
0.975

0.995

0.957

0.965

0.972

0.961

0.911

0.866

0.974

0.928

0.998

0.988

0.952

0.977

0.977

0.971

0.980

0.959

0.965

0.904

0.974

0.911

0.906

0.963

0.895

0.918

0.916

0.933

0.957

0.915

0.893

0.935

0.943

0.972

0.909

0.697

0.903

0.982

0.526

0.717

0.538

0.572

0.425

0.516

0.852

0.849

0.784

0.823

0.510

0.452

0.536

0.432

0.809

0.403

0.625

0.850

0.964

0.754

0.474

0.414

0.898

0.919

0.616

0.848

0.8028
$0.256 \quad 0.280$

$0.363 \quad 0.365$

$0.481 \quad 0.319$

$0.575 \quad 0.397$

$0.462-0.395$

$0.556 \quad 0.493$

$\begin{array}{ll}0.587 & 0.458\end{array}$

$0.364 \quad 0.281$

$0.366 \quad 0.224$

$0.391 \quad 0.230$

$0.483 \quad 0.319$

$0.331 \quad 0.217$

$0.525 \quad 0.498$

$0.452 \quad 0.361$

$0.566 \quad 0.469$

$0.569 \quad 0.443$

$0.698 \quad 0.568$

$0.639 \quad 0.516$

$0.348 \quad 0.240$

$0.326 \quad 0.343$

$0.346 \quad 0.270$

$0.316 \quad 0.483$

$0.396 \quad 0.500$

$0.351 \quad 0.470$

$0.449 \quad 0.648$

$0.563 \quad 0.462$

$0.335 \quad 0.373$

$0.387 \quad 0.417$

$0.292 \quad 0.309$

$0.167 \quad 0.168$

$0.403 \quad 0.407$

$0.471 \quad 0.532$

$0.501 \quad 0.440$

$0.327 \quad 0.412$

$0.575 \quad 0.392$

$0.303 \quad 0.198$

$0.466 \quad 0.366$

$0.934 \quad 0.859$

$0.883 \quad 0.807$

$0.920 \quad 0.551$

$0.695 \quad 0.958$

$0.844 \quad 0.930$

$0.791 \quad 0.891$

$0.230 \quad 0.351$

$0.528 \quad 0.659$

$0.406 \quad 0.395$

$0.354 \quad 0.388$

$0.885 \quad 0.973$

$0.924 \quad 0.908$

$0.924 \quad 0.797$

$0.823 \quad 0.785$

$0.575 \quad 0.620$

$0.841 \quad 0.866$

$0.680 \quad 0.735$

$0.642 \quad 0.708$

$0.624 \quad 0.687$

$0.693 \quad 0.934$

$0.697 \quad 0.964$

$0.848 \quad 0.897$

$0.388 \quad 0.750$

$0.352 \quad 0.737$

$0.649 \quad 0.804$

$0.243 \quad 0.247$

$0.5628 \quad 0.5464$

Mean

Notes: The table shows the title of the 64 occupations, the percentage of individuals employed in it and the fraction of individuals that report performing analytical, manual and interactive tasks on their job following the classification of Autor et al (2003). For a description of the tasks underlying the three aggregate task groups, see Table B2.

Source: IAB Employee Sample, matched with Qualification and Career Survey: 1979, 1985, 1991/2, 1997/8. 
Table B3: Selection of Occupational Movers

\begin{tabular}{|c|c|c|c|c|c|c|}
\hline \multirow[b]{2}{*}{ Y: Log Daily Wage in $t$} & \multicolumn{2}{|c|}{ Low-Skilled } & \multicolumn{2}{|c|}{ Medium-Skilled } & \multicolumn{2}{|c|}{ High-Skilled } \\
\hline & (1) & $(2)$ & $(1)$ & $(2)$ & $(1)$ & $(2)$ \\
\hline Occupational Move in $t+1$ & $\begin{array}{c}-0.1090 \\
(0.0026)^{\star \star}\end{array}$ & & $\begin{array}{c}-0.1134 \\
(0.0012)^{\star \star}\end{array}$ & & $\begin{array}{c}-0.1246 \\
(0.0032)^{\star \star}\end{array}$ & \\
\hline Distance to Target in $\mathrm{t}+1$ & & $\begin{array}{c}-0.8163 \\
(0.0834)^{\star *}\end{array}$ & & $\begin{array}{c}-1.0098 \\
(0.0462)^{\star \star}\end{array}$ & & $\begin{array}{c}-1.9494 \\
(0.1691)^{\star \star}\end{array}$ \\
\hline Actual Experience & $\begin{array}{c}0.0691 \\
(0.0010)^{\star \star}\end{array}$ & $\begin{array}{c}0.0593 \\
(0.0016)^{\star \star}\end{array}$ & $\begin{array}{c}0.0430 \\
(0.0004)^{\star \star}\end{array}$ & $\begin{array}{c}0.0440 \\
(0.0010)^{\star *}\end{array}$ & $\begin{array}{c}0.0844 \\
(0.0012)^{\star \star}\end{array}$ & $\begin{array}{c}0.1020 \\
(0.0030)^{\star *}\end{array}$ \\
\hline Experience Squared & $\begin{array}{c}-0.0025 \\
(0.0001)^{\star \star}\end{array}$ & $\begin{array}{c}-0.0021 \\
(0.0001)^{\star \star}\end{array}$ & $\begin{array}{c}-0.0015 \\
(0.0000)^{\star \star}\end{array}$ & $\begin{array}{c}-0.0015 \\
(0.0001)^{\star \star}\end{array}$ & $\begin{array}{c}-0.0032 \\
(0.0001)^{\star \star}\end{array}$ & $\begin{array}{c}-0.0040 \\
(0.0002)^{\star \star}\end{array}$ \\
\hline Occupational Tenure & $\begin{array}{c}0.0112 \\
(0.0006)^{\star \star}\end{array}$ & $\begin{array}{c}0.0206 \\
(0.0010)^{\star \star}\end{array}$ & $\begin{array}{c}0.0093 \\
(0.0003)^{\star \star}\end{array}$ & $\begin{array}{c}0.0211 \\
(0.0005)^{\star \star}\end{array}$ & $\begin{array}{c}0.0095 \\
(0.0009)^{\star \star}\end{array}$ & $\begin{array}{c}0.0190 \\
(0.0020)^{\star *}\end{array}$ \\
\hline Year Dummies & Yes & Yes & Yes & Yes & Yes & Yes \\
\hline Occupation Dummies & Yes & Yes & Yes & Yes & Yes & Yes \\
\hline Observations & 202,978 & 44,119 & 919,584 & 117,204 & 179,354 & 20,917 \\
\hline
\end{tabular}


Table B4: First-Stage Results for Instrumental Variable Estimator in Table 7

\begin{tabular}{|c|c|c|c|c|c|c|c|c|c|c|c|c|}
\hline & \multicolumn{4}{|c|}{ Panel A: Low Skilled } & \multicolumn{4}{|c|}{ Panel B: Medium Skilled } & \multicolumn{4}{|c|}{ Panel C: High Skilled } \\
\hline & $\begin{array}{l}\text { Actual } \\
\text { Experience } \\
(10)\end{array}$ & $\begin{array}{c}\text { Actual } \\
\text { Experience }^{2} \\
(10)\end{array}$ & $\begin{array}{l}\text { Occupational } \\
\text { Tenure } \\
(10)\end{array}$ & $\begin{array}{l}\text { Task } \\
\text { Tenure } \\
(10) \\
\end{array}$ & $\begin{array}{l}\text { Actual } \\
\text { Experience } \\
(10) \\
\end{array}$ & $\begin{array}{l}\text { Actual } \\
\text { Experience }{ }^{2} \\
(10)\end{array}$ & $\begin{array}{l}\text { Occupational } \\
\text { Tenure } \\
(10)\end{array}$ & $\begin{array}{l}\text { Task } \\
\text { Tenure } \\
(10) \\
\end{array}$ & $\begin{array}{c}\text { Actual } \\
\text { Experience } \\
(10)\end{array}$ & $\begin{array}{c}\text { Actual } \\
\text { Experience }^{2} \\
(10)\end{array}$ & $\begin{array}{l}\text { Occupational } \\
\text { Tenure } \\
(10)\end{array}$ & $\begin{array}{l}\text { Task } \\
\text { Tenure } \\
(10) \\
\end{array}$ \\
\hline Potential Labor Market Experience & $\begin{array}{c}0.584 \\
(0.025)^{\star \star \star}\end{array}$ & $\begin{array}{c}-0.523 \\
0.556\end{array}$ & $\begin{array}{c}0.270 \\
(0.026)^{\star \star \star}\end{array}$ & $\begin{array}{c}0.409 \\
(0.023)^{\star \star \star}\end{array}$ & $\begin{array}{c}0.696 \\
(0.012)^{\star \star \star}\end{array}$ & $\begin{array}{c}-0.597 \\
(0.277)^{\star \star}\end{array}$ & $\begin{array}{c}0.421 \\
(0.018)^{\star \star \star}\end{array}$ & $\begin{array}{c}0.555 \\
(0.013)^{\star \star \star}\end{array}$ & $\begin{array}{c}0.411 \\
(0.037)^{\star \star \star}\end{array}$ & $\begin{array}{l}-2.594312 \\
(0.684)^{\star \star \star}\end{array}$ & $\begin{array}{c}0.2532097 \\
(0.042)^{\star \star \star}\end{array}$ & $\begin{array}{c}0.322 \\
(0.035)^{\star \star \star}\end{array}$ \\
\hline Potential Experience Squared & $\begin{array}{c}0.004 \\
(0.002)^{\star \star}\end{array}$ & $\begin{array}{c}0.517 \\
(0.0358)^{\star \star \star}\end{array}$ & $\begin{array}{l}-0.002 \\
(0.002)\end{array}$ & $\begin{array}{c}0.003 \\
(0.001)^{\star \star}\end{array}$ & $\begin{array}{c}0.003 \\
(0.001)^{\star \star \star}\end{array}$ & $\begin{array}{c}0.662 \\
(0.021)^{\star \star \star}\end{array}$ & $\begin{array}{l}-0.001 \\
-0.001\end{array}$ & $\begin{array}{c}0.003 \\
(0.0009)^{\star \star \star}\end{array}$ & $\begin{array}{c}0.010 \\
(0.002)^{\star \star \star}\end{array}$ & $\begin{array}{c}0.6108764 \\
(0.031)^{\star \star \star}\end{array}$ & $\begin{array}{l}0.0002 \\
(0.002)\end{array}$ & $\begin{array}{c}0.008 \\
(0.002)^{\star \star \star}\end{array}$ \\
\hline Fraction of Job Leavers in Occupation & $\begin{array}{c}-18.673 \\
(10.175)^{\star}\end{array}$ & $\begin{array}{l}-108.066 \\
-187.168\end{array}$ & $\begin{array}{c}-23.088 \\
(11.386)^{\star \star}\end{array}$ & $\begin{array}{l}-17.922 \\
(9.591)^{\star}\end{array}$ & $\begin{array}{r}2.526 \\
-3.519\end{array}$ & $\begin{array}{r}51.588 \\
-57.887\end{array}$ & $\begin{array}{l}-0.225 \\
-5.381\end{array}$ & $\begin{array}{r}0.287 \\
-3.905\end{array}$ & $\begin{array}{c}21.034 \\
(15.377)\end{array}$ & $\begin{array}{l}581.1816 \\
(281.57)^{\star \star}\end{array}$ & $\begin{array}{c}26.634 \\
(17.277)\end{array}$ & $\begin{array}{c}27.5229 \\
(14.412)^{\star}\end{array}$ \\
\hline Fraction of New Jobs in Occupation & $\begin{array}{l}-5.182 \\
(4.493)\end{array}$ & $\begin{array}{c}-116.646 \\
-81.480\end{array}$ & $\begin{array}{c}-8.357 \\
(5.046)^{\star}\end{array}$ & $\begin{array}{c}-8.173 \\
(4.223)^{\star}\end{array}$ & $\begin{array}{c}-8.211 \\
(1.934)^{\star \star \star}\end{array}$ & $\begin{array}{c}-98.733 \\
(32.008)^{\star \star \star}\end{array}$ & $\begin{array}{c}-14.185 \\
(2.923)^{\star \star \star}\end{array}$ & $\begin{array}{c}-10.881 \\
(2.120)^{\star \star \star}\end{array}$ & $\begin{array}{l}-12.653 \\
(7.666)^{\star}\end{array}$ & $\begin{array}{c}-182.4908 \\
(140.369)\end{array}$ & $\begin{array}{l}-20.887 \\
(8.613)^{\star \star}\end{array}$ & $\begin{array}{l}-15.8936 \\
(7.185)^{\star \star}\end{array}$ \\
\hline Size of Occupation (in percent) & $\begin{array}{c}25.961 \\
(10.038)^{\star \star}\end{array}$ & $\begin{array}{r}266.088 \\
-185.498\end{array}$ & $\begin{array}{c}39.776 \\
(11.259)^{\star \star \star}\end{array}$ & $\begin{array}{c}33.407 \\
(9.493)^{\star \star \star}\end{array}$ & $\begin{array}{c}7.233 \\
(3.668)^{\star \star}\end{array}$ & $\begin{array}{r}63.018 \\
-60.125\end{array}$ & $\begin{array}{c}11.254 \\
(5.504)^{\star \star}\end{array}$ & $\begin{array}{c}10.904 \\
(4.019)^{\star \star \star}\end{array}$ & $\begin{array}{c}4.915 \\
(15.309)\end{array}$ & $\begin{array}{l}-205.1424 \\
(280.313)\end{array}$ & $\begin{array}{c}7.272 \\
(17.200)\end{array}$ & $\begin{array}{c}4.8697 \\
-14.3478\end{array}$ \\
\hline Distance to all Occupations (mean) & $\begin{array}{c}125.555 \\
(65.994)^{\star}\end{array}$ & $\begin{array}{c}2570.638 \\
(1204.01)^{\star \star}\end{array}$ & $\begin{array}{l}114.313 \\
(73.600)\end{array}$ & $\begin{array}{c}108.411 \\
(61.428)^{\star}\end{array}$ & $\begin{array}{r}27.425 \\
-23.827\end{array}$ & $\begin{array}{c}366.273 \\
-402.098\end{array}$ & $\begin{array}{c}-65.459 \\
(34.883)^{\star}\end{array}$ & $\begin{array}{c}11.708 \\
-26.337\end{array}$ & $\begin{array}{c}-181.318 \\
(88.869)^{\star \star}\end{array}$ & $\begin{array}{l}-3195.295 \\
(1627.24)^{\star \star}\end{array}$ & $\begin{array}{c}1.396 \\
(99.848)\end{array}$ & $\begin{array}{r}-101.457 \\
(83.290)\end{array}$ \\
\hline 10\% Most Distant Occupations & $\begin{array}{c}-6.088 \\
(4.3184)\end{array}$ & $\begin{array}{c}-110.210 \\
-82.859\end{array}$ & $\begin{array}{c}-8.653 \\
(5.049)^{\star}\end{array}$ & $\begin{array}{c}-8.894 \\
(4.242)^{\star \star}\end{array}$ & $\begin{array}{c}0.399 \\
-1.668\end{array}$ & $\begin{array}{r}11.956 \\
-28.400\end{array}$ & $\begin{array}{l}-3.436 \\
-2.415\end{array}$ & $\begin{array}{l}-2.856 \\
-1.795\end{array}$ & $\begin{array}{c}1.143 \\
(5.890)\end{array}$ & $\begin{array}{l}-24.36747 \\
(107.858)\end{array}$ & $\begin{array}{c}12.632 \\
(6.618)^{\star}\end{array}$ & $\begin{array}{c}8.260 \\
(5.521)\end{array}$ \\
\hline Maximum Distance & $\begin{array}{c}25.028 \\
(12.078)^{\star \star}\end{array}$ & $\begin{array}{c}517.311 \\
(234.94)^{\star \star}\end{array}$ & $\begin{array}{c}54.246 \\
(17.442)^{\star \star}\end{array}$ & $\begin{array}{c}36.712 \\
(13.542)^{\star \star \star}\end{array}$ & $\begin{array}{c}1.847 \\
-4.260\end{array}$ & $\begin{array}{c}59.575 \\
-77.576\end{array}$ & $\begin{array}{c}19.638 \\
(6.382)^{\star \star \star}\end{array}$ & $\begin{array}{c}7.700 \\
-4.848\end{array}$ & $\begin{array}{c}-0.487 \\
(15.496)\end{array}$ & $\begin{array}{l}104.7358 \\
(283.734)\end{array}$ & $\begin{array}{c}17.090 \\
(17.410)\end{array}$ & $\begin{array}{c}0.001 \\
(14.523)\end{array}$ \\
\hline Distance to Job Openings (mean) & $\begin{array}{l}-108.981 \\
(65.253)^{\star}\end{array}$ & $\begin{array}{l}-2180.145 \\
(1189.73)^{\star}\end{array}$ & $\begin{array}{l}-98.556 \\
-73.063\end{array}$ & $\begin{array}{l}-91.896 \\
(60.852)\end{array}$ & $\begin{array}{l}-21.931 \\
-23.734\end{array}$ & $\begin{array}{l}-238.537 \\
-400.357\end{array}$ & $\begin{array}{c}69.248 \\
(34.509)^{\star \star}\end{array}$ & $\begin{array}{l}-6.837 \\
-26.178\end{array}$ & $\begin{array}{c}218.999 \\
(88.241)^{\star \star}\end{array}$ & $\begin{array}{c}3901.804 \\
(1615.74)^{\star \star}\end{array}$ & $\begin{array}{c}-4.217 \\
(99.142)\end{array}$ & $\begin{array}{l}119.518 \\
(82.702)\end{array}$ \\
\hline Observations & 5789 & 5789 & 5789 & 5789 & 21012 & 21012 & 21012 & 21012 & 2609 & 2609 & 2609 & 2609 \\
\hline R2 First-Stage & 0.61 & 0.52 & 0.13 & 0.47 & 0.71 & 0.66 & 0.24 & 0.57 & 0.33 & 0.64 & 0.33 & 0.62 \\
\hline Shea's Partial R2 Instruments & 0.0042 & 0.0801 & 0.0023 & 0.0019 & 0.0026 & 0.1966 & 0.0017 & 0.0013 & 0.0118 & 0.1002 & 0.0023 & 0.0044 \\
\hline $\begin{array}{l}\text { F-Test of Excluded Instruments } \\
P \text { value }\end{array}$ & $\begin{array}{l}800.17 \\
(0.0000)\end{array}$ & $\begin{array}{l}383.39 \\
(0.0000)\end{array}$ & $\begin{array}{c}95.57 \\
(0.0000)\end{array}$ & $\begin{array}{c}466.84 \\
(0.0000)\end{array}$ & $\begin{array}{l}4098.85 \\
(0.0000)\end{array}$ & $\begin{array}{c}2099 \\
(0.0000)\end{array}$ & $\begin{array}{c}654.97 \\
(0.0000)\end{array}$ & $\begin{array}{l}2290.04 \\
(0.0000)\end{array}$ & $\begin{array}{l}304.05 \\
(0.0000)\end{array}$ & $\begin{array}{l}282.61 \\
(0.0000)\end{array}$ & $\begin{array}{l}212.56 \\
(0.0000)\end{array}$ & $\begin{array}{c}41.96 \\
(0.0000)\end{array}$ \\
\hline $\begin{array}{l}\text { Anderson-Rubin IV Relevance Test } \\
\text { P value }\end{array}$ & \multicolumn{4}{|c|}{$\begin{array}{c}10.71 \\
(0.0978)\end{array}$} & \multicolumn{4}{|c|}{$\begin{array}{c}28.35 \\
(0.0001)\end{array}$} & \multicolumn{4}{|c|}{$\begin{array}{c}5.98 \\
(0.4250)\end{array}$} \\
\hline $\begin{array}{l}\text { AR Overidentification Test } \\
P \text { value }\end{array}$ & \multicolumn{4}{|c|}{$\begin{array}{c}8.313 \\
(0.1398)\end{array}$} & \multicolumn{4}{|c|}{$\begin{array}{c}21.863 \\
(0.0006)\end{array}$} & & & & \\
\hline
\end{tabular}

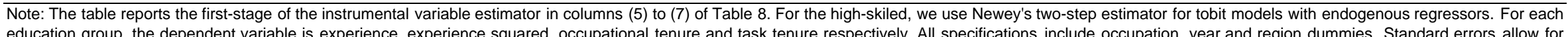

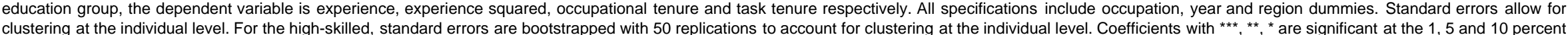
level respectively. See also notes to Table 8. 